\title{
El valor social y las cofradías canarias: una aproximación a través del análisis de un caso
}

\section{Beatriz Guzmán-Pérez Javier Mendoza Jiménez Maㅡ Victoria Pérez Monteverde}

RESUMEN: Las entidades de economía social han sido reconocidas como pieza clave en la agenda de desarrollo sostenible, pero aún sigue siendo necesario avanzar en la cuantificación de la aportación efectiva que realizan a la comunidad local. Este trabajo trata de medir el valor social de una de las familias de la economía social cuyo impacto socio-económico no ha sido abordado por los estudios empíricos realizados al respecto, las cofradías de pescadores. El contexto geográfico de la investigación es el archipiélago canario, empleándose la contabilidad social (Retolaza et al., 2016) como métrica del valor social. Se trata de un sistema de información ampliado que permite configurar una base de variables extrapolables a este tipo de entidades en otros territorios, y mostrar que la contribución que realizan las cofradías a sus stakeholders va más allá de variables económicas, y apoyan las funciones de sostenimiento del sector pesquero que les han sido asignadas por la normativa nacional y autonómica.

PALABRAS CLAVE: Cofradías de pescadores, Valor Social, Contabilidad social, Sostenibilidad, Canarias

CLAVES ECONLIT: B55, M40, M14, Q56, P22.

Cómo citar este artículo/How to cite this article: GUZMÁN-PÉREZ, B., MENDOZA, J. \& PÉREZ, M.V. (2020): "El valor social y las cofradías canarias: una aproximación a través del análisis de un caso", CIRIEC-España, Revista de Economía Pública, Social y Cooperativa, 100, 115-153. DOI: 10.7203/CIRIEC-E.100.14486.

Correspondencia: Beatriz Guzmán Pérez, beatriz.guzman@universidadeuropea.es, ORCID: 0000-0002-2441-6137); Javier Mendoza Jiménez, jmendoz@ull.edu.es, ORCID: 0000-00027158-8724; María Victoria Pérez Monteverde, mvperez@ull.edu.es, ORCID: 0000-0002-48012137. Universidad de La Laguna, Universidad Europea de Canarias. 


\section{Expanded abstract}

\section{The social value and fishermen guilds in the canary islands: an approximation through the analysis of a case.}

The Social Economy entities of have been highlighted by the scientific literature for their potentiality to propitiate the generation of a social value in the territories that are located, which would allow the strengthening of cohesion, employment and economic growth, respecting ecological limits (Bono , 2012; Chaves and Monzón, 2012). From an institutional perspective, they are considered a key piece in the global action plan aimed at achieving sustainability (United Nations General Assembly, 2015: 12; Opinion 2009 / C 318/05 of the European Social and Economic Committee: 26 ), thus, urging to evaluate the contribution that, in its different dimensions, they make to the local environment (European Commission, 2011a, b; GECES, 2012; SEC, 2011).

The fishermen's guilds, conceived as unions of fishermen who, gathered around an entity or organization, try to achieve specific objectives of the activity they carry out (Cervera, 2006), have received less attention in the field of Social Economy, despite its explicit recognition as a key piece in comprehensive sustainability (FAO, 2016: 138).

This work aims to fill this relative deficiency. Its main objective is to make visible the integral contribution that these entities make to the local community, as a previous step to integrate the generation of social value for sustainability in the management of these regional organizations. The geographical context of the study is the Canary Islands, an outermost region of the European Union, where inshore and artisanal fishing have a long historical tradition (Galván, 1982; Santamaría et al., 2014). Of the fishermen's guilds that remain active in this island complex, one of them has been taken as a case study, using the Social Accounting system as a metric of social value (Retolaza et al., 2016).

The Social Accounting system is an information system that complements and expands the scope of traditional accounting in a double dimension, both in terms of the nature of the value considered and the interest groups contemplated. It is characterized by allowing to objectify in a single monetary measure the economic and social value attributable to management, the integrated social value or blended value (Emerson and Bonini, 2003), and to satisfy the information demands of its stakeholders (Freeman, 1984: 24).

In this article, the five-stage methodological process established by Retolaza et al., (2016:4043) has been followed. In the first phase, according to action research methodology, the work team is formed and it determines the problem to be solved and establishes the project schedule. In a second stage, following the theory of the stakeholders, the organization's interest groups are identified and represented on a map. Third, according to the phenomenological 
perspective, the representatives of the different groups are interviewed to determine their interests and, after grouping them into the variables of perceived social value, they are oriented to indicators, obtaining the matrix of interests of the stakeholders.

In the fourth stage, the instruments of fuzzy logic allow to identify the organization's outputs linked to the value variables, to select proxies, and to generate algorithms to quantify in monetary terms the two ecosystems of social value, the market and the specific. The proxies of the direct socio-economic value are standardized (Retolaza et al., 2016: 44-46) and those of the indirect one are obtained by carrying out an economic-financial analysis of the entity's portfolio of suppliers (Retolaza et al., 2015: 40). In the fifth and final stage of the methodological process, the non-market social value is consolidated with the social market value, complemented by feedback of the results to facilitate the improvement processes in the organization.

To apply the described methodology, a team of five members was formed (three researchers from the University of the province, the senior employer and the administrative officer of the brotherhood), which identified up to six types of stakeholders. Interviews were conducted with six interlocutors, representatives of shipowners' providers ( $100 \%$ of the total of this group), providers ( $20 \%$ of the total), workers (50\%), Canary Islands Oceanographic Institute (one researcher), and shipowners (10\%). With the results obtained in these interviews, up to seven different value variables are obtained, including issues such as the service provided by the brotherhood, support for scientific research and the brand strength of the entity for its partners.

Once the value variables were obtained, instruments of the fuzzy logic were used to express in monetary terms the social value of the Brotherhood. First, regarding the specific social value or non-market value, the organization's outputs linked to the value variables are identified through an intersubjective reflection process, co-participated by the group of research team agents, agreeing upon decisions on transformation of variables.

Subsequently, proxies, or external items that allow an approximation to the monetary value that the outputs could have, were selected, taking into account the similarity or consideration of the social and temporal context in which the outputs are generated. Since, in the polyhedral model of social value analysis, the choice of proxies is made applying the reasonable value (Retolaza and San José, 2018: 109), using as an approximation the market price of an identical or similar output, taking into account the specific nature of the output.

The direct socio-economic value of the brotherhood amounts to $€ 36,611.07$, while its indirect socio-economic value amounts to $€ 604.93$, with impact rates of $21.9 \%$ in personnel costs and $25.4 \%$ of added value. The consolidation of these data to achieve Integrated Social Value yields a result of $€ 103,133.32$, which is notable coming from a negative operating result of $€$ 8,069.19. In the distribution of the External and Internal Integrated Social Value, disaggregated by typologies of social value, to the entity's interest groups, it is observed that the groups that receive the greatest social return are the Public Administration and the shipowners. Furthermore, the entity's contribution to the generation and distribution of value to local suppliers and research organizations is relevant.

The shortage in number of entities in the sample is one of the major limitations of this study. Regarding the possibility of extrapolating the value variables that have been identified 
by adopting an external approach to other brotherhoods, it must be taken into account that the approach to social value from the ontological approach of stakeholder theory is distinguished by its differential nature. Each brotherhood is considered, therefore, as a differentiated unit, capable of having to respond to a peculiar and specific set of interests, which may, in addition, vary over time.

Likewise, the choice of proxies poses certain limitations when extrapolating the case study to other brotherhoods in Spanish territory. In particular, although the specific financial items presented here could be taken as a reference, they would have to be referred to the geographic and temporal spaces in which the outputs are generated. In any case, and in coherence with the phenomenological approach, more cases of entities similar to the one in question would be required that, taken together, would also allow progress in standardization, both of proxies and values.

The main contribution of this study is probably to have revealed certain aspects that, once corroborated after an analysis similar to an aggregate set of entities of the same nature, would allow public and private decision-making to be oriented towards increasing effectiveness of the Brotherhoods for sustainable performance. Specifically, it is worth highlighting three value variables associated with the entity's mission, implying a recognition in the 21st century of the contribution to society of an entity of medieval origin: the service provided to its members, the ecological knowledge of the fishermen, and the prestige for the organizations of the 21st century that they use their products. In any case, the proxies proposed for the monetization of the outputs, linked to such value variables, should take into account the spatio-temporal realities in which they were generated.

This work follows the recent empirical research line started by authors like Bassi and Vincenti (2015); Etxezarreta et al. (2018); Monzón et al. (2013); and Retolaza et al. (2015). This research quantifies the socio-economic impact of Social Economy organizations with the purpose of increasing efficiency and effectiveness in their management, taking into account their peculiarities. 


\section{Introducción}

Las entidades de economía social han sido realzadas por la literatura científica por su potencialidad para propiciar la generación de un valor social en los territorios que se emplazan, que posibilitaría el reforzamiento de la cohesión, el empleo y el crecimiento económico, respetando los límites ecológicos (Bono, 2012; Chaves y Monzón, 2012). Desde una perspectiva institucional, se las considera una pieza clave en el plan de acción global encaminado al logro de la sustentabilidad (Asamblea General de las Naciones Unidas, 2015:12; Dictamen 2009/C 318/05 del Comité Social y Económico Europeo:26), instándose a evaluar la aportación que, en sus distintas dimensiones, realizan al entorno local (Comisión Europea, 2011a,b; GECES, 2012; SEC, 2011).

La medición de esta contribución a la sostenibilidad entraña, sin embargo, ciertas dificultades, por ser el impacto socio-económico (Monzón, 2013) o valor social (Retolaza et al., 2016) una variable latente en el sentido de Everit (1984). Desde distintas aproximaciones se han desarrollado sistemas que lo hacen posible (Nachar, 2013), habiendo sido aplicados a distintas familias de entidades de naturaleza social (Bassi y Vincenti, 2015, Etxezarreta et al., 2018, Monzón et al., 2013) mayoritariamente cooperativas y fundaciones.

Las cofradías de pescadores, concebidas como uniones de pescadores que, congregados en torno a una entidad u organización, tratan de alcanzar objetivos propios de la actividad que realizan (Cervera, 2006), han recibido una menor atención en el ámbito de la economía social, a pesar de su reconocimiento explícito como pieza clave en la sostenibilidad integral (FA0, 2016:138).

Este trabajo viene a suplir dicha carencia relativa, y plantea como objetivo principal hacer visible la aportación integral que estas entidades realizan a la comunidad local, como paso previo para integrar la generación de valor social para la sostenibilidad en la gestión de estas organizaciones regionales. El contexto geográfico del estudio es el archipiélago canario, región ultraperiférica de la Unión Europea, en la que la pesca de bajura y artesanal cuenta con una larga tradición histórica (Galván, 1982; Santamaría et al., 2014). De las cofradías de pescadores que permanecen activas en este conjunto insular, se ha tomado una de ellas como caso de estudio, utilizándose como métrica del valor social el sistema de la Contabilidad Social (Retolaza et al., 2016).

La estructura de este estudio es la siguiente: en el apartado 2 se muestra una síntesis de la revisión de los trabajos que, desde distintos enfoques, abordan la problemática que aquí ocupa -el valor social de las organizaciones, las cofradías de pescadores y los sistemas de medición del impacto socio-económico-, planteándose los objetivos de investigación. En el apartado 3 se describe a la población, el caso de análisis, y el sistema de la Contabilidad Social (Retolaza et al., 2016). Los resultados de la investigación se exponen en el apartado 4 y, en el 5, la discusión y las conclusiones. 


\section{Marco teórico y objetivos de investigación}

\subsection{El valor social de las organizaciones y las entidades de economía social}

La concepción de las organizaciones como sistemas abiertos (Katz y Kahn, 1966) supone su reconocimiento como entidades que, en su interacción con la realidad y el medio que les rodea, establecen flujos reales, financieros y de información con sus stakeholders (Freeman, 1984). Independientemente de que su propósito sea la obtención de la máxima rentabilidad para los propietarios del capital (Friedman, 1970), la creación de valor para los grupos de interés (Freeman et al., 2004) o la influencia trascendente en la sociedad de la que forman parte (Duska y Ragatz, 2008; Melé, 2009), lo cierto es que, con el ejercicio de su actividad económico-productiva, generan utilidades de naturaleza económico-financiera para los accionistas, y socio-económicas y medioambientales para la comunidad local (Emerson et al., 2003; Porter y Kramer, 2011).

Los trabajos científicos suelen referirse a esta incidencia de las organizaciones en la sociedad con los términos de impacto socio-económico (Monzón, 2013), impacto social (Ayuso, 2018; Díaz et al., 2012), valor compartido (Porter y Kramer, 2011) o valor social (Bassi y Vincenti, 2015; Retolaza et al., 2016; Tuan, 2008). Siguiendo esta corriente de la literatura, en este estudio se concibe el valor social de una organización como la aportación que realiza en forma de rendimientos financieros a los stakeholders, y la repercusión social, económica y ambiental al conjunto de la sociedad (Retolaza et al., 2016).

Entre el conjunto de entidades, las de economía social han sido reconocidas por su potencialidad para propiciar la generación de un valor social en los territorios en que se emplazan, que posibilitaría el reforzamiento de la cohesión, el empleo y el crecimiento económico, respetando los límites ecológicos (Bono, 2002:192; Chaves y Monzón, 2012:19). Este tipo de entidades son realzadas por considerárselas pieza clave en el logro de un desarrollo sostenible (Asamblea General de las Naciones Unidas, 2016:12; Dictamen 2009/C 318/05 del Comité Social y Económico Europeo:26), definido como "la capacidad para satisfacer las necesidades del presente sin comprometer la capacidad de las generaciones futuras para satisfacer sus propias necesidades" (World Commission on Environment and Development, 1987), contemplando una triple vertiente medioambiental, económica y social (United Nations, 2002).

Estas organizaciones se erigen en palancas de dinamización social sustentable, esencialmente por los principios y valores que les son característicos ${ }^{1}$ (Chaves y Monzón, 2018:14). En concreto, tres de sus rasgos internos organizativos -la finalidad de servir a los asociados y/o a la colectividad, un proceso decisional en el que participan de forma equilibrada socios

1. Recogidos en la Carta de Principios de la Economía Social aprobada en 2002 por el Comité Europeo Permanente de las Cooperativas, las Mutualidades, las Asociaciones y las Fundaciones (CEP-CMAF). 
y agentes interesados en el objeto de la entidad, y la priorización de las personas y el trabajo frente al capital en la posible distribución de beneficios y excedentes-, han sido especialmente distinguidos por posibilitar a estos entes el ejercicio de unas funciones sociales, económicas y políticas en el sistema económico que contribuirían al logro de un crecimiento sustentable y socialmente integrador (Chaves y Monzón, 2012:13-14; Macías, 2018:13-15).

\subsection{Las cofradías de pescadores}

Las cofradías de pescadores tienen una larga tradición histórica en España, siendo su origen previo al de los gremios (Cervera, 1988). La primera de la que se tiene constancia surge durante el reinado de Fernando I, rey de Castilla y León (1037-1065), en el municipio cántabro de Laredo (Varona, 1995:51 en Cervera, 1988:82). El modelo organizativo en el que se basa se extiende por el territorio español ${ }^{2}$ (Cervera, 1988), llegando a las Islas Canarias tras su colonización (Cervera, 2006).

Generalmente eran los propios pescadores quienes, bajo el influjo y apoyo de la doctrina social de la Iglesia ${ }^{3}$, promovían el nacimiento de las cofradías para facilitar el ejercicio de su oficio a través de prácticas colaborativas, realizaban funciones comunitarias en beneficio de sus asociados y participaban en el desarrollo de una parte marginal de población con escasos recursos, ligada a la explotación del mar y vinculada a pequeñas pesquerías artesanales (Cervera, 2010).

Estas entidades han tratado de considerar por igual a todos los cofrades, sean armadores o marineros, evolucionando hacia sistemas de representación paritaria de los intereses de ambos (Cervera, 1988:83). Han mostrado una alta capacidad de auto-organización y de resolución interna de conflictos, logrando establecer formas de relación entre sus miembros y con los recursos comunes en un intento de controlar el esfuerzo pesquero, y acordar artes y prácticas a emplear en el ejercicio de la pesca, mayoritariamente de bajura o artesanal (Pascual, 1999:343-345, Botana y Millán, 2016:121).

Los estudios académicos sobre las cofradías se han centrado sobre todo en aspectos históricos y sociales, como su papel en la inmigración (Antelo, Villa y Santos, 2018), pero también destacan su naturaleza público-privada (García Lorenzo y Varela Lafuente, 2019), la gestión socio ambiental que realizan en general (Calderón Gil, 2018), su influencia socioeconómica en la pesca (Méndez, 2018) e incluso la colaboración con la comunidad científica (Vidal et al., 2020).

Legalmente, las cofradías quedan definidas en el artículo 45 de la Ley 3/2001, de 26 de marzo, de Pesca Marítima del Estado, modificada por la Ley 33/2014, de 26 de diciembre, como corporaciones de derecho público ${ }^{4}$, sin ánimo de lucro, representativas de los intereses económicos de sus socios, dotadas de personalidad jurídica plena y capacidad de obrar para el cum-

2. Se tiene constancia, por ejemplo, del nacimiento de la cofradía de pescadores de Tortosa (Tarragona) en 1116, la de Lequeitio (Vizcaya) en 1325 o la de la Albufera de Valencia en 1393.

3. Parece que la relación de convivencia en los pueblos pesqueros giraba en torno a ideas religiosas que inducían a mantener la unión frente a enemigos potenciales, lo que favorecía la advocación a un determinado santo al que nombraban patrón (Cervera, 2006).

4. No quedan encuadradas, no obstante, en la organización estatal. 
plimiento de sus fines. Es competencia de las Comunidades Autónomas la regulación de estos agentes ${ }^{5}$, siendo la Ley $17 / 2003$, de 10 de abril, de Pesca de Canarias, y su Reglamento, aprobado por el Decreto 182/2004, de 21 de diciembre, la que en Canarias ordena su actuación ${ }^{6}$.

El ordenamiento jurídico del sector pesquero establece como órganos rectores y representativos de las cofradías de pescadores la junta general -órgano de gobierno y decisión-, el cabildo -de gestión y administración-, y el patrón mayor -órgano unipersonal de dirección-. Los cargos de todos ellos son elegidos entre los propios miembros de la cofradía, mediante sufragio libre, igual y secreto, debiendo ajustarse su actuación a principios democráticos ${ }^{7}$. En un intento de salvaguardar la diversidad de intereses de los cofrades por la naturaleza de su condición, ha de respetarse, siempre que sea posible, la paridad de representación entre trabajadores y armadores, así como la proporcionalidad entre los distintos sectores representativos de la producción o modalidades de pesca.

Asimismo, este marco regulador reconoce a las cofradías el ejercicio de ciertas funciones específicas de naturaleza económica, social y ecológica ${ }^{8}$ que, de forma sintética, podrían agruparse en dos categorías generales, unas que hacen posible a estos agentes participar en la gobernanza de la pesca, y otras que atienden al fin social que los caracteriza?.

1) Entre las funciones del primer grupo, ha de destacarse que las cofradías actúan como órganos de consulta y colaboración de las administraciones competentes en materia de pesca marítima y de ordenación del sector pesquero, participando en la preparación, elaboración y aplicación de normas y disposiciones de carácter general que afectan al sector pesquero, especialmente en los ámbitos bajo su influencia ${ }^{10}$. Se reconoce tam-

5. La atribución de facultades jurídicas a las autonomías en materia pesquera hace posible que el marco normativo regional contemple las particularidades del desarrollo de la actividad pesquera artesanal en los territorios en los que las cofradías se emplazan.

6. Este marco jurídico de ámbito nacional y autonómico está alineado con las directrices y principios que regulan la pesca y los océanos en la Unión Europea (UE), esto es, la Política Pesquera Común (UE, 2013) y la Política Marítima Integrada (UE, 2013). La primera de ellas pretende el logro de la sostenibilidad integral de la pesca y la acuicultura, la seguridad alimentaria y salubridad de los alimentos que de ellas resultan, una industria pesquera dinámica, así como un nivel de vida equitativo para las comunidades pesqueras. Por su parte, la Política Marítima Integrada busca el fomento de una toma de decisiones coordinada y coherente en materia marítima y la cooperación internacional, en aras del logro del máximo desarrollo sostenible, crecimiento económico y cohesión social en los Estados miembros, en particular de las regiones costeras, insulares y ultraperiféricas de la Unión, y los sectores marítimos.

7. Las votaciones para la adopción de acuerdos en la junta general y el cabildo rectores se llevan a cabo a mano alzada, salvo que dos tercios de sus miembros acuerden la votación secreta. Con carácter general, los acuerdos se adoptan por mayoría simple, considerándose de calidad el voto del patrón mayor, en caso de empate.

8. Recogidas en los artículos 46 y 87 de la Ley 3/2001 de 26 de marzo, de Pesca Marítima del Estado, modificada por la Ley 33/2014, de 26 de diciembre, el artículo 38 de Ley 17/2003, de 10 de abril, de Pesca de Canarias, y el artículo 85 de su Reglamento, aprobado por Decreto 182/2004, de 21 de diciembre.

9. Para una mejor realización de cualquiera de ellas, pueden establecer convenios de colaboración entre sí o con otras entidades.

10. No es sólo un deber de información impuesto, que opera sobre las actividades en las que las cofradías tengan un conocimiento especial, sino que constituye también un derecho de estas, por cuanto la administración deba contar con su parecer y opinión cuando se elaboren disposiciones que les afecten (Barrio, 1998:171). 
bién la participación de estos agentes en la ordenación y organización del proceso de comercialización de los productos de la pesca, marisqueo y acuicultura ${ }^{11}$.

Dentro de este grupo de funciones, puede incluirse su papel como agente de apoyo para el control administrativo ${ }^{12}$, prestación de servicio público, aplicación de la política pesquera comunitaria, y gestión de zonas y bienes de dominio público marítimo-terrestre que le fueran concedidas para su aprovechamiento. Han de apoyar también a los equipos de investigación marítima y oceanográfica, facilitando actuaciones a bordo de los buques y aportando información.

2) En cuanto al fin social que las caracteriza, han de asesorar y orientar a los cofrades sobre el contenido de la normativa pesquera, prestar servicios sociales, recreativos, culturales 0 análogos, y promover actividades de formación en materias específicas de su profesión.

Para el cumplimiento de estas funciones las cofradías deben administrar y gestionar sus recursos propios y patrimonio. La contabilidad de estas entidades ha de ser ordenada y adecuada a su actividad, estando regida por los principios contables de veracidad, claridad, exactitud, responsabilidad y publicidad.

Las dimensiones de contexto interno que las caracterizan, por ser coherentes con los principios orientadores de las entidades de economía social, han propiciado su distinción jurídica como entes de esta naturaleza en la Ley 5/2011, de 29 de marzo, de Economía Social ${ }^{13}$. En concreto, atendiendo a tales principios (Defourny y Develtere, 1999), están presentes en ellas los de prevalencia de las personas, la aplicación de los resultados en función del trabajo, la solidaridad interna y la independencia respecto a los poderes públicos.

Por su naturaleza, se encuadran pues dentro del núcleo duro de la economía social, formado por cooperativas, mutualidades y asociaciones (De Mendiguren, Etxarri y Aldanondo, 2008), compartiendo la mayoría de las características de las primeras, a excepción de la ausencia de ánimo de lucro. En las cofradías se ponen también de manifiesto los problemas que, por lo general, son comunes a otros tipos de entidades de la economía social, como es el reto de la profesionalización (García Allut y Freire, 2006).

Dos aspectos fundamentales que las distinguen del resto de las organizaciones de naturaleza social son la especialización en un único sector, el pesquero, y la obligación de colaboración con los poderes públicos. Debido a las exigencias legales que han de atender, se han dotado de una estructura vertical, que incluye a todas las personas relacionadas con el proceso de la pes-

11. Su concurrencia en este punto de la cadena de suministro no se limita a la primera venta de pescado fresco, sino que se extiende a las mejoras de las condiciones de la venta y revalorización de la producción, la promoción de los productos pesqueros y el fomento de la transformación y la conservación de tales alimentos.

12. Velando por el estricto cumplimiento de la normativa vigente en materia de pesca marisqueo, acuicultura, y de descarga, primera venta, y comercialización de los recursos marinos, cuando tengan asignados estos servicios.

13. Esta ley cita en su preámbulo que las cofradías de pescadores comparten los principios orientadores de la economía social, siendo éstos la primacía de las personas y del fin social sobre el capital, la aplicación de los resultados obtenidos de la actividad económica principalmente en función del trabajo aportado por los socios y al fin social objeto de la entidad, la promoción de la solidaridad interna y con la sociedad, y la independencia respecto a los poderes públicos (artículo 4 de la Ley 5/2011). 
ca (Alegret, 1989), armadores y marineros legalmente habilitados y voluntariamente afiliados a una cofradía en particular.

Como entidades representativas de los intereses del sector de la pesca artesanal y de bajura, han sido reconocidas en el ámbito institucional internacional como pieza clave en la sostenibilidad integral (FAO, 2016:138). A este respecto, las organizaciones regionales de pescadores son consideradas agentes de vital importancia tanto en la Iniciativa sobre el Crecimiento Azul ${ }^{14}$ -programa de acción de la Organización de las Naciones Unidas para la Alimentación y la Agricultura (FAO) que respalda la sustentabilidad global ${ }^{15}(\mathrm{UN}, 2012)$ a través de medidas que impulsan específicamente la sostenibilidad de los océanos-, como en la Estrategia de Crecimiento Azul -estrategia a largo plazo de la Unión Europea de apoyo al crecimiento sostenible de los sectores marino y marítimo (COM, 2012)-.

En particular, las cofradías de pescadores son fundamentales en la agenda internacional para la consecución de unos mares sostenibles por dos razones. En primer lugar, las características intrínsecas de la actividad económico-productiva que desarrollan -los equipos empleados, las técnicas y artes en que se basa, la estructura organizativa y de propiedad que, generalmente, conlleva, y unos usos y costumbres enraizados en la cultura local-, les permiten abastecer de alimentos, ingresos y empleo de forma sustentable (Boza, 2015:3; Pascual, 1999:343).

En segundo lugar, la participación efectiva de estas organizaciones en la gobernanza de la pesca permitiría integrar el conocimiento ecológico tradicional de los pescadores -de naturaleza tácita y ser el resultado de la acumulación de información a lo largo de generaciones (García Allut, 1999; Hernández, 2014; Pascual, 1999)-, en la gestión operacional a corto plazo, y la elaboración y planificación a largo plazo de las políticas pesqueras, y en última instancia, impulsaría los pilares ambiental y social de la sostenibilidad. De forma adicional, en la medida en que dicha participación permita obtener una mayor renta económica a quienes ejercen este oficio, reforzaría también la vertiente económica de la sustentabilidad (FA0, 2016:140).

\subsection{La medición del valor social}

En la actualidad, las organizaciones, independientemente de su naturaleza, están realizando un notable esfuerzo por integrar en sus sistemas de gestión mecanismos que permitan evaluar el impacto social que generan, principalmente para atender y dar respuesta a las demandas de sus stakeholders (Ayuso, 208:3-4, Bassi et al., 2015:12-14). Las instituciones internacionales y europeas han instado a las entidades de economía social a medir la aportación que, en sus

14. Se trata de un programa diseñado en torno a la pesca de captura y la acuicultura sostenible, los medios de vida y los sistemas alimentarios y el crecimiento económico derivado de los servicios de los ecosistemas acuáticos (FAO, 2016). El Código de Conducta para la Pesca Responsable (FAO, 1995) y el enfoque ecosistémico de la pesca son los elementos sobre los que se apoya dicha iniciativa.

15. En la Conferencia de las Naciones Unidas sobre el Desarrollo Sostenible Río +20 se acuñó el término Economía Azul para poner de relieve la trascendencia de la sostenibilidad de los océanos en la consecución de un desarrollo sostenible. 
distintas dimensiones, realizan al entorno local (Comisión Europea, 2011a,b; GECES, 2012; SEC, 2011), básicamente por las dos razones que a continuación se exponen.

En primer lugar, la susodicha cuantificación permitiría a estas entidades acceder a fuentes de inversión responsables que, por incluir entre sus criterios indicadores de tipo social, faciliten la financiación necesaria para el ejercicio de su actividad y, por tanto, la consecución real de los efectos macroeconómicos que de ellas se espera (Chaves y Monzón, 2012; Díaz et al., 2012:181-182). En segundo lugar, las autoridades económicas, tras la agregación de datos, podrían definir acciones específicas que contribuyesen a eliminar las barreras operativas que, en su caso, presenten los agentes de economía social y que, en la práctica, limiten la cohesión social y territorial que podrían desencadenar (Monzón, 2013:158).

La determinación del impacto social de las entidades de cualquier naturaleza entraña, no obstante, ciertas dificultades, por ser dicho valor o aportación a la sustentabilidad una variable latente en el sentido de Everit (1984) ${ }^{16}$. Desde distintas aproximaciones se han desarrollado sistemas que lo hacen posible ${ }^{17}$, como son el Balance del Bien Común (Felber, 2010), el Índice de Capacidades (Garriga, 2014), el Key Performance Indicators, KPIs. (Monzón et al., 2013), el Social Added Value Evaluation, S.A.V.E. (Bassi y Vincenti, 2015), la Contabilidad Social (Retolaza et al., 2014) o el Social Return on Investment, S.R.O.I., desarrollado por el fondo estadounidense Roberts Enterprise Development Fund, REDF. Estas métricas han sido aplicadas a diversas familias de entidades de economía social, fundamentalmente cooperativas (Bassi y Vincenti, 2015; Etxezarreta et al., 2018; Monzón et al., 2013), y fundaciones y organizaciones sin ánimo de lucro (Retolaza et al., 2015; Retolaza y San-Jose, 2016).

Si bien no existe una visión compartida sobre la conveniencia de una herramienta específica que a priori sea especialmente idónea para evaluar el desempeño social del conglomerado de entidades que conforman la economía social (Ebrahim y Rangan, 2010; Etxezarreta et al., 2018: 160), desde distintos enfoques sí se ha reconocido que ciertos elementos deben guiar la elección de un sistema concreto entre los posibles. En concreto, puede destacarse el tipo de objetivos que se persiguen con la medición (Asociación Española de Fundaciones, 2015; Comisión Europea, 2015), la confluencia con la aproximación subyacente al enfoque (Bouchard, 2010:10), la conceptualización de la economía social (Díaz et al., 2012:186), o el modelo y origen de la entidad cuyo valor social se desea evaluar (Díaz et al., 2012:187).

\subsection{Objetivos de investigación}

Esta revisión de la literatura permite identificar como objetivo principal de este estudio medir el valor social para la sostenibilidad generado por las cofradías de pescadores, con el fin último de integrarlo en su gestión. Es preciso disponer de esta información, como forma de orientar la toma de decisiones hacia el desempeño sostenible de esta rama del sector pesquero. Lo

16. En la cadena de valor del impacto social (Rosenzweig, 2004:6-7) puede constatarse que el impacto o valor no puede ser observado de manera directa, aunque sí algunas de sus manifestaciones.

17. Pueden consultarse las síntesis de Ayuso (2018), Nachar (2013) u Olsen \& Galimidi (2008). 
anterior posibilitaría el diseño y la puesta en práctica de acciones específicas, que redundaran en una mayor efectividad de estas entidades de economía social y, por consiguiente, en un aumento del bienestar social y de la sostenibilidad de las comunidades en que se emplazan.

Este trabajo se suma a la línea de investigación empírica reciente que cuantifica el impacto socio-económico de las organizaciones de economía social, con el propósito de incrementar la eficiencia y la eficacia en su gestión, teniendo en cuenta sus peculiaridades (Bassi y Vincenti, 2015; Etxezarreta et al., 2018; Monzón et al., 2013; Retolaza et al., 2015).

\section{Las cofradías de pescadores en Canarias. La contabilidad social}

\subsection{Contexto geográfico y población}

El ámbito geográfico de este estudio es el archipiélago canario, una de las Comunidades Autónomas del Reino de España, considerada como región ultraperiférica de la Unión Europea, situada frente a la costa noroeste del continente africano, a 100 kilómetros de la frontera entre Marruecos y Sáhara occidental. Su origen es volcánico, cuenta con 8 islas principales, 3 islotes y 2 rocas, y $1.379 \mathrm{~km}$ de longitud de litoral -el 18,38\% del total nacional- (Instituto Canario de Estadística 2019). Sus aguas jurisdiccionales lindan con tres fronteras marítimas nacionales, Portugal, Marruecos y Sáhara Occidental, disponiendo de la mayor Zona Económica Exclusi$\mathrm{va}^{18} \mathrm{a}$ escala nacional (Suárez de Vivero, 2011).

Este conjunto insular se ubica en el paso de la corriente marítima fría de Canarias, que regula el clima y determina las características oceanográficas de la zona. Está poblada por un gran número de especies endémicas y migratorias o transfronterizas, y es considerada un ecosistema único de importancia mundial (Popescu y Ortega, 2013:15).

Un rasgo particular de la corriente canaria es que posee una zona de ascensión, a lo largo de la costa occidental africana, a la que llegan aguas frías profundas y ricas en nutrientes, que estimulan la productividad primaria y, por ende, la del resto de niveles de la cadena trófica marina (Popescu y Ortega, 2013:16-17). La productividad de las aguas oceánicas que rodean a las islas es menor, debido a sus condiciones oligotróficas y a la estrechez de la plataforma continental insular, por el origen volcánico del archipiélago $0^{19}$ (Santamaría et al., 2014:11).

18. La zona económica exclusiva, es una franja marítima que se extiende desde el límite exterior del mar territorial, o sector del océano en el que un Estado tiene plena soberanía, hasta una distancia de 200 millas náuticas (370,4 km), contadas a partir de la línea de base desde la que se mide la anchura de éste.

19. Las condiciones marítimas en las cercanías de la costa son, además, similares a las de mar abierto, por ser la batimetría del fondo marino que rodea a las islas mayoritariamente abrupta y, la plataforma continental, estrecha y con pendiente pronunciada (Popescu y Ortega, 2013:9). 
La actividad pesquera tiene un bajo peso económico en la estructura productiva canaria. Según datos del Instituto Canario de Estadística (ISTAC), el valor a precios de mercado de la producción del sector primario fue de 561.841 miles de euros en 2017, el 1,3\% del PIB regional.

La producción total de productos pesqueros en el archipiélago, registrada mediante el sistema de primera venta ${ }^{20}$, ascendió a 21.827.046 kg en 2017 (ISTAC). En términos de volumen, la mayor parte corresponde a los productos frescos (63,4\% en 2017), seguidos de los procedentes de la acuicultura $(35,8 \%)$ y pesca congelada $(0,8 \%)$.

En cuanto a la flota empleada para la extracción de estos recursos, según datos del Ministerio de Agricultura y Pesca, Alimentación y Medio Ambiente (MAPAMA), en los puertos canarios hay operativos, a 31 de diciembre de 2017, un total de 774 buques, con características técnicas medias de eslora $(9,94$ metros), arqueo $(29,24 \mathrm{GT})$ y potencia $(66,69 \mathrm{Kw})$ inferiores a la nacional (10,87 metros, 36,50 GT y $85,56 \mathrm{Kw}$, respectivamente). De esta flota con base en Canarias, 738 son buques que faenan en el caladero insular, de artes menores ${ }^{21}$ (94\%) y atuneros cañeros (6\%).

El elevado peso de la pesca artesanal y de bajura en el conjunto de la actividad pesquera en Canarias es reflejo de una larga tradición histórica en la región (Galván, 1982; Santamaría et al., 2014), y forma parte de la identidad de muchos de sus pueblos (Popescu y Ortega, 2013:17). Según el Plan Estratégico Nacional 2007-2013 del Fondo Europeo de la Pesca (MAPAMA, 2007), 30 de los 89 municipios canarios son dependientes de esta actividad productiva.

Los marineros y armadores de la autonomía canaria, al igual que los del resto de España, se asocian voluntariamente a las cofradías de pescadores activas que, según datos de la Consejería de Agricultura, Ganadería y Pesca del Gobierno de Canarias, ascienden a 25 en 2018. En Tenerife, la mayor de sus islas, se ubican 10 de estas entidades de economía social, el 40\% de las existentes en el archipiélago.

\subsection{Caso de estudio}

Tras haber realizado un filtrado de las organizaciones canarias de pescadores, y mantenido entrevistas previas para comprobar su disponibilidad ${ }^{22}$, se ha tomado como caso de estudio una de ellas, emplazada en la costa meridional de la isla Tenerife, con jurisdicción territorial próxima a dos municipios dependientes de la actividad pesquera (MAPAMA, 2007:162). En su ámbito territorial se ubican seis puertos, competencia de distintos niveles administrativos.

20. Debe tenerse en cuenta que el sistema de primera venta es una herramienta de trazabilidad de las capturas, y no implica en ningún caso transacción económica alguna. Por tanto, el valor en euros que este sistema refleja es una aproximación al valor real de mercado de la producción pesquera registrada.

21. Las artes menores autorizadas en Canarias son el cerco (traíña, chinchorro y red salamera), el enmalle (trasmallo y cazonal), la trampa (nasa y tambor), el anzuelo y la red izada (pandorga).

22. El contacto inicial y filtrado de entidades se llevó a cabo en enero y febrero de 2018. 
Las dependencias y domicilio fiscal de la entidad analizada se encuentran en un puerto dotado de una completa dotación de infraestructuras ${ }^{23}$, óptimas condiciones de atraque, fondeo e instalaciones en tierra, y un tráfico de barcos de pesca de los mayores de la zona.

El censo de la cofradía está compuesto por 138 socios, mayoritariamente marineros $(60,1 \%)$, de los segmentos de pesca de artes menores (79\%) y atuneros (31\%). El 43,5\% de los asociados lleva afiliado a esta entidad más de 20 años, habiéndose dado de alta en la última década el 39,9\% de los censados. En los puertos sitos en su jurisdicción se registran un total de 67 buques, de artes menores (88\%) y atuneros (12\%), predominando los de eslora inferior a 10 metros (64\%).

En cuanto a la composición de los órganos rectores, los estatutos establecen 16 miembros en la junta general y 6 vocales en el cabildo, además del patrón mayor y del vicepatrón mayor. La estructura organizativa se completa con dos trabajadores laborales.

Las concesiones demaniales de la cofradía son la grúa, el travel lift y el taller de reparación, cuya vigilancia y conservación debe garantizar. No dispone de concesión de primera venta y, en el puerto en el que se emplaza, tampoco existe un punto que permita el registro del pescado fresco. Los asociados a la entidad, con base de operaciones en el mismo, deben transportar los productos pesqueros para su etiquetado. Cumplido este requisito normativo, pueden iniciar la comercialización, realizada de forma autónoma por los cofrades.

La entidad obtiene los ingresos de las cuotas abonadas por los socios, la prestación del servicio de varadero y la venta de material de pesca, remanente de 2008. La situación económico-financiera desde 2010 es de desahucio, perteneciendo a la Autoridad Portuaria provincial las dependencias en las que se ubica ${ }^{24}$.

Esta debilidad financiera le impide acceder al sistema de subvenciones y desarrollar acciones de interés social y cultural para sus socios y la comunidad local. Afronta sus operaciones diarias dotando deterioros por créditos comerciales incobrables de forma individualizada, que posteriormente revierte por la parte cobrada o que ha pasado a clientes, y contrata servicios a créditos. Los volúmenes de compras a los proveedores son escasos, todos locales.

\subsection{La Contabilidad Social}

En este trabajo se utiliza el sistema de la Contabilidad Social (Retolaza et al., 2016) para cuantificar el valor social de la cofradía de estudio. Se trata de un sistema de información que complementa y amplía el tradicional en una doble dimensión, tanto en cuanto a la naturaleza del valor considerado como a los grupos de interés contemplados. Se caracteriza por permitir objetivar en una única medida monetaria el valor económico y social atribuible a la gestión, el

23. En concreto, el puerto dispone de dique de abrigo, escollera, balizamiento, muelle, iluminación, grúa, travel lift, explanada, pequeño almacén, taller de reparación, acceso por carretera, toma de agua y electricidad. Sin embargo, no dispone de frigoríficos, camión isotermo, astilleros ni toma de gasoil (Santamaría et al., 2014).

24. La apertura y el cierre del local, necesarios para la prestación de servicios por la cofradía, son gestionados de forma directa y diaria por la citada autoridad. 
valor social integrado o blended value (Emerson y Bonini, 2003), y satisfacer las demandas de información de sus stakeholders (Freeman, 1984:24).

En el ámbito de la economía social, este sistema de información ampliado ha sido empleado para determinar el impacto socio-económico que genera la Economía Social en general (Lazcano et al., 2019) diversas familias de entidades que la componen, tales como cooperativas agrarias (Etxezarreta et al., 2018) y de crédito (Retolaza et al., 2018), fundaciones (Retolaza et al., 2015; Retolaza et al., 2014), u organizaciones sin ánimo de lucro (Retolaza y San-José, 2016a), no habiéndose aplicado aún a la de las cofradías de pescadores. Fuera de este ámbito, la Contabilidad Social se ha empleado en campos tan dispares como las universidades (Ayuso et. al, 2020) y los hospitales (San-José, et al., 2019).

La Contabilidad Social (Retolaza et al., 2016) se desarrolla sobre la base de un análisis coste-beneficio (Mishan, 2007) y las cuatro siguientes hipótesis metodológicas: (1) un proceso de investigación de action research (Lewin, 1946), caracterizado por la combinación de teoría y práctica, que implica la resolución de un problema a partir de la construcción participativa de nuevo conocimiento (Retolaza et al., 2016:17); (2) una aproximación al concepto del valor social desde la perspectiva ontológica de la teoría de los stakeholders (Freeman, 1984; Retolaza y San-José; 2011), que permite concretar el valor social de una entidad que genera a sus grupos de interés ${ }^{25}$; (3) el paradigma fenomenológico (Husserl, 1990), que conlleva considerar el valor social como un constructo elaborado de forma subjetiva por los stakeholders destinatarios de dicho valor (Retolaza et al., 2016:20); y (4) la hipótesis de la lógica difusa (Zadeh, 1965), que permite monetizar el valor social haciendo uso de instrumentos propios de los sistemas de conjuntos borrosos, como son la similitud como criterio de asignación entre los dos conjuntos de objetos mentales, o la aplicación del criterio de Hurwicz (1951) para la selección del valor (Retolaza et al., 2016:24).

El modelo de análisis del valor social que resulta de la unificación de hipótesis anteriores, el modelo poliédrico o Social Value Polyhedral Model (SPOLY) (Retolaza et al., 2016), permite el control de la gestión del valor social en las organizaciones. Se trata de un modelo analítico-sintético cuya representación gráfica podría considerarse semejante a una flor (Figura 1): el círculo interior recoge el valor social que la organización genera y es reconocido como tal por sus grupos de interés, y los pétalos, el valor identificado por un determinado grupo de interés y que no confluye con el resto.

El blended value está integrado en este modelo por dos componentes o ecosistemas de valor social, el valor socio-económico o valor social de mercado, y el valor social específico o de no mercado. El primero de ellos hace referencia al valor social que la organización genera con la realización de su actividad económica, siendo transferido como contrapartida de un precio real de mercado (y recogido en la contabilidad de la organización). Este valor de mercado se considera de forma amplia, estando conformado por el valor añadido que, de forma directa, una organización genera y distribuye, y por el valor que, de forma indirecta, genera con las compras de insumos (Retolaza et al., 2016). El segundo de los componentes, el valor social

25. Quienes participan y resultan afectados por la actividad de la organización. 
específico o de no mercado, es concebido como el valor transferido por la organización a sus grupos de interés sin contrapartida de precio real de mercado.

Para la cuantificación del valor social integrado, se sigue un proceso metodológico que consta de cinco etapas (Retolaza et al., 2016:40-43). En la primera fase, de acuerdo con la action research, se forma el equipo de trabajo, quien determina el problema a resolver y establece el cronograma del proyecto. En una segunda etapa, siguiendo la teoría de los stakeholders, se identifican a los grupos de interés de la organización, y se representan en un mapa. En tercer lugar, conforme a la perspectiva fenomenológica, se entrevistan a los representantes de los distintos colectivos para determinar sus intereses y, tras la agrupación de éstos en las variables del valor social percibido, se orientan a indicadores, obteniéndose la matriz de intereses de los stakeholders.

En la cuarta etapa, los instrumentos de la lógica difusa permiten identificar los outputs de la organización vinculados a las variables de valor, seleccionar las proxys, y generar algoritmos para cuantificar en términos monetarios los dos ecosistemas de valor social, el de mercado y el específico, aunque las proxys del valor socio-económico directo están estandarificadas (Retolaza et al., 2016:44-46) y las del indirecto se obtienen realizando un análisis económico-financiero de la cartera de proveedores de la entidad (Retolaza et al., 2015:40). En la quinta y última etapa del proceso metodológico, se consolida el valor social de no mercado con el valor social de mercado, complementándose con el feedback de los resultados para facilitar los procesos de mejora en la organización.

\section{Figura 1. Modelo Poliédrico de Análisis del Valor Socia.}

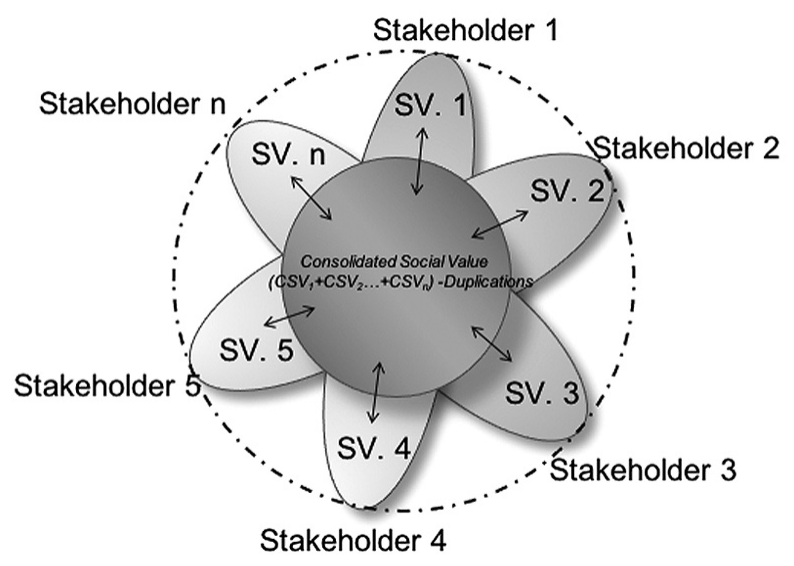

Fuente: Retolaza et al. (2015:51). 
La Contabilidad Social constituye una métrica del valor social especialmente apropiada para este estudio, teniendo en cuenta el objetivo principal planteado. En concreto, la aproximación subjetiva para la objetivación del valor social en que se basa está conceptualmente alineada con la filosofía de la sustentabilidad (WCED, 1987), por enfocarse en los outputs generados por una entidad y percibidos como valor por sus stakeholders ${ }^{26}$.

\section{Resultados}

A continuación, se muestran los resultados alcanzados al aplicar la Contabilidad Social (Retolaza et al., 2006) al caso de estudio, especificando los obtenidos en cada una de las fases del proceso.

\subsection{Primera etapa: formación del equipo de Action Research y cronograma de trabajo}

En primer lugar, se forma el equipo de Action Research (AR) en marzo de 2018, estando compuesto por un total de cinco miembros - tres investigadores de la Universidad de la provincia, el patrón mayor y el administrativo de la cofradía-. Los representantes de la entidad transmiten una insatisfacción con el estado de la determinación de su valor actual, y se identifica como problema a resolver visibilizar el valor íntegro que genera, más allá de su pérdida económica, para comunicarla a la Administración Pública. Teniendo presente el tamaño de la entidad, el alcance de sus actividades, y los recursos con los que el equipo externo cuenta, se establece un cronograma de trabajo de 6 meses.

\subsection{Segunda etapa: identificación de los stakeholders de la cofradía de pescadores}

Posteriormente, se identifican a los grupos de interés de la entidad. Esta labor se realiza por los investigadores del equipo de AR, en una primera fase, empleando las fuentes de información secundarias disponibles, externas (marco jurídico nacional y autonómico del sector pesquero) e internas (documentos de la cofradía). Posteriormente, se entrevista a los representantes de la entidad del equipo de AR. Las evidencias primarias recogidas permiten concretar a los distintos colectivos, y consensuar su representación en el mapa de stakeholders de la Figura 2. La descripción de los agentes identificados se recoge en la Tabla 1.

26. En otros ámbitos, como el del turismo, se lleva a cabo también la medición de la sostenibilidad a través de una aproximación fenomenológica -identificación de los stakeholders del destino turístico y posterior análisis de sus valores, percepciones e intereses (Poudel et al., 2016; Randle y Hoye, 2016)-. 


\section{Figura 2. Mapa de stakeholders de la cofradía de pescadores}

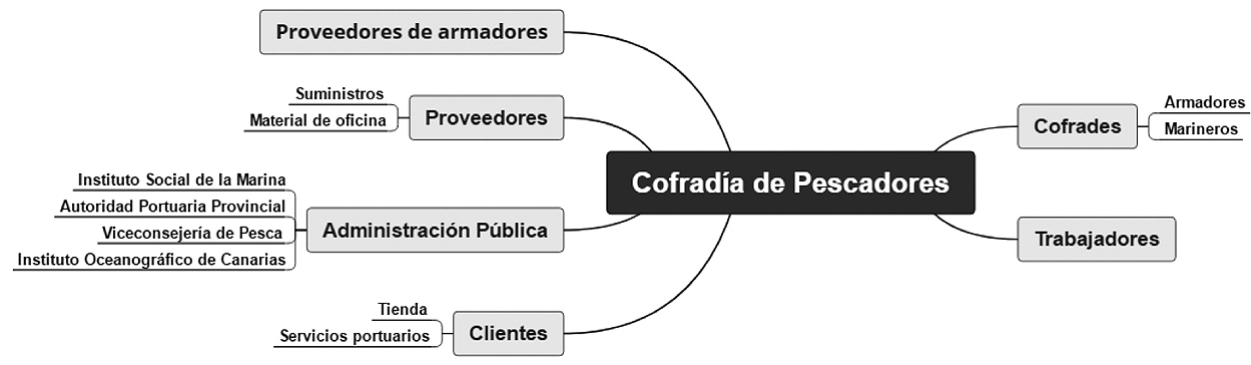

Fuente: Elaboración propia.

\section{Tabla 1. Descripción de los stakeholders de la cofradía de pescadores}

\begin{tabular}{ll} 
Stakeholders & Descripción \\
\hline Cofrades & $\begin{array}{l}\text { Son la esencia y naturaleza de ser de la cofradía. El cumplimiento de las } \\
\text { condiciones establecidas reglamentaria y estatutariamente, junto con el abono } \\
\text { de una cuota mensual, otorga a los socios ciertos derechos y obligaciones. La } \\
\text { cofradía defiende sus intereses y lleva a cabo las actividades encomendadas } \\
\text { por la normativa pesquera nacional y autonómica, excepto las de interés social } \\
\text { y cultural. }\end{array}$ \\
\hline Trabajadores & $\begin{array}{l}\text { Están especializados funcionalmente, uno en labores administrativas y } \\
\text { comerciales, y otro en la prestación del servicio de grúa y vigilancia y } \\
\text { mantenimiento de las concesiones demaniales. }\end{array}$ \\
\hline Clientes & $\begin{array}{l}\text { Demandan a la entidad el servicio de grúa, travel lift, reparación, limpieza } \\
\text { y calzado de buques, y adquisición de material remanente de pesca y de }\end{array}$ \\
\hline embarcaciones.
\end{tabular}

Fuente: Elaboración propia. 


\subsection{Tercera etapa: identificación de las variables de valor}

En esta fase se trabaja con la percepción de los stakeholders previamente identificados, puesto que la hipótesis de la perspectiva fenomenológica implica considerar el valor social como un constructo elaborado de forma subjetiva por los destinatarios de dicho valor (Retolaza et al., 2016:20). Se trata de comprender el significado que tiene, para las personas que se relacionan o se ven afectadas por la Cofradía, lo que para ellas supone la experiencia de interacción con la entidad, o lo que de ella resulta (Fuster, 2019). Esta comprensión resulta crucial para poder monetizar, en la etapa posterior, el valor social de no mercado.

Se analiza la totalidad del fenómeno para el agente pesquero utilizando muestras pequeñas tomadas de los diferentes grupos de interés, examinadas en profundidad (Easterby-Smith, Thorpe y Lowe, 1991). Se trata de limitar las posibles discrepancias entre la percepción de los stakeholders de la entidad y la realidad a través de un proceso de triangulación (Retolaza et al., 2016:20), utilizando la información contenida en los documentos internos de la organización pesquera, la regulación del sector, y la obtenida a través de la observación directa.

Ha de precisarse que no resulta posible entrevistar al conjunto de representantes de los colectivos prioritarios, según el listado propuesto por los miembros de la Cofradía integrantes del AR. En concreto, las limitaciones de tiempo y de recursos, impiden aplicar dicha técnica de recolección de datos a los interlocutores de la Viceconsejería de Pesca del Gobierno de Canarias, el Instituto Social de la Marina, la Autoridad Portuaria Provincial, clientes y marineros.

Para solventar esta dificultad, se decide proceder de forma similar a otros casos en los que la misma se ha presentado (Retolaza et al., 2016b:126-127). En el que aquí ocupa, se han combinado la perspectiva externa (enfoque resultados / outputs) e interna (visión de costes / gastos). Esto es, las evidencias de las fuentes primarias con las que cuenta se utilizan para determinar el valor percibido por los grupos de interés entrevistados (perspectiva externa). Y se complementa dicha información con las fuentes secundarias disponibles para consensuar primero, entre los miembros externos del equipo de AR y la Cofradía, alguna de las variables, y determinar, después, el valor para los grupos de interés no entrevistados (perspectiva interna).

Antes de aplicar esta técnica específica de recolección de datos, se tiene cuenta que sus respuestas podrían estar condicionadas por la presencia de ciertos aspectos referidos al entrevistador, como son que generalmente se ve lo que se espera ver, que los datos son casi siempre para una u otra hipótesis, que nunca se observa todo lo que se podría haber observado, y que la observación es siempre selectiva y siempre hay una correlación funcional entre la teoría y los datos (Trejo, 2012:100).

Para crear una atmósfera que permitiera la adecuada conducción de la entrevista, y se lograse reflejar la realidad vivida por la persona entrevistada de la forma más auténtica posible, previamente el investigador participa en un proceso de epojé (Husserl, 1990) o liberación consciente de prejuicios culturales, tradicionales o teóricos, que pudieran evitar que el entre- 
vistado formulase la respuesta esperada, o restringiese la interpretación de su experiencia ${ }^{27}$ (Fuster, 2019). Se prepara también una guía para la entrevista y el cuestionario a realizar, con base en el de Retolaza et al. (2016:73-74).

En la fase descriptiva de la aproximación fenomenológica, con el propósito de detallar de la manera más completa y no prejuiciosa el fenómeno en estudio, se cuidan especialmente los siguientes aspectos (Giorgi y Giorgi, 2003): a) que reflejase la realidad como se presentó; b) que fuese lo más completa posible y no omitiera nada que pudiera tener relevancia para el estudio; c) que no contuviera elementos proyectados por el observador; y d) que recogiese el fenómeno descrito en su contexto. Ha de indicarse, por último, que la descripción protocolar se transcribe en el momento en que se realiza la entrevista, habiéndose prescindido de grabaciones para evitar que la presencia de un magnetófono pudiera coartar al interlocutor en sus respuestas.

La segunda fase de dicha aproximación, consistente en la estructuración analítica de las descripciones contenidas en los protocolos, supone la ejecución de una sucesión de pasos entrelazados para la identificación de las variables de valor, su orientación a indicadores y la obtención de la matriz de variables de valor (Retolaza et al., 2016:21). En concreto, se agrupa el conjunto de valores percibidos en áreas temáticas, integrando expresiones sinónimas, afines o con fuertes similitudes en cada una de ellas, y se identifica la variable de valor focalizada en las distintas áreas.

Se expresa también el contenido de las variables de valor en un lenguaje técnico o científico que permitiese su orientación a indicadores y que, en la etapa siguiente, pudieran vincularse con outputs mensurables generados por la entidad y sobre los que también se intuyera que sería posible obtener proxys externos a la misma. Las evidencias primarias con las que se cuenta permiten llevar a cabo este proceso de transformación de forma manual y directa ${ }^{28}$.

Por su parte, para la identificación de las variables de valor de los colectivos no entrevistados, se analiza la información contenida en las fuentes secundarias -normas jurídicas que regulan el sector y documentos internos de la entidad-, desde el punto de vista de lo que las actividades realizadas por la Cofradía podrían suponer para los distintos agentes. Las variables resultantes de este proceso interno fueron consensuadas por el equipo de AR.

27. Aunque es cierto que a un entrevistador externo le resulta más fácil acercarse al entrevistado desprovisto de prejuicios y dispuesto a escuchar desde cero, se consideró conveniente hacer ese proceso previo de epojé. En concreto, se puso en práctica estableciendo los presupuestos, hipótesis, preconceptos desde los cuales se partía, y reconociendo que podrían intervenir sobre la investigación. Asimismo, se reflexionó sobre las concepciones teóricas sobre las que está estructurado el marco teórico que orienta esta investigación. Todo ello, a través de respuestas a las cuestiones postuladas sobre las actitudes, valores, creencias, presentimientos, conjeturas e interés en relación con la investigación, para evitar que estuviesen presentes en la interpretación de las experiencias.

28. Debe de tenerse en cuenta, que existen instrumentos, como el análisis MICMAC, desarrollado por el Instituto LIPSOR de la Universidad de París, o los mapas mentales elaborados con Mindjet, Freemind o Novamind, que, además de ayudar en la transformación de las variables de valor, confieren mayor grado de objetividad y rigurosidad al análisis (Retolaza y San José, 2016b:91). 


\section{Tabla 2. Descripción de las variables de valor}

\begin{tabular}{ll} 
Variables de valor & Descripción \\
\hline Servicio & $\begin{array}{l}\text { Recoge el valor para los armadores y marineros del asesoramiento, la } \\
\text { tramitación de documentos el Instituto Social de la Marina e información } \\
\text { de ayudas y subvenciones de la Viceconsejería de Pesca; la centralización } \\
\text { de compras, a los armadores; y el servicio de varadero, a los clientes y } \\
\text { armadores. }\end{array}$ \\
\hline Ventaja de precio & $\begin{array}{l}\text { Los socios y clientes obtienen utilidad por la adquisición de productos } \\
\text { a un precio de venta inferior al de mercado: los armadores, el calzado, } \\
\text { la limpieza de embarcaciones y el travel lift; el conjunto de socios, y los } \\
\text { clientes y socios, el material de pesca en tienda. }\end{array}$ \\
\hline Divulgación & $\begin{array}{l}\text { Recoge el traslado de la realidad del sector y de los problemas de los } \\
\text { cofrades a la Viceconsejería de Pesca, apreciado por los afiliados. Incluye } \\
\text { también la utilidad para la Viceconsejería de Pesca e Instituto Social de la } \\
\text { Marina de los datos que la entidad registra y comunica. }\end{array}$ \\
\hline Apoyo & $\begin{array}{l}\text { Valor para la Viceconsejería de Pesca y la Autoridad Portuaria de las } \\
\text { labores de la entidad de vigilancia y conservación de las infraestructuras } \\
\text { públicas concedidas para su explotación y el soporte para la puesta en } \\
\text { práctica de la política pesquera común, así como el brindado a los equipos } \\
\text { de investigación. }\end{array}$ \\
\hline Conocimiento & $\begin{array}{l}\text { Utilidad para la Viceconsejería de Pesca de disponer de información directa } \\
\text { de la realidad del sector. Y para el Instituto Oceanográfico de Canarias por } \\
\text { la posibilidad de contar con el saber de los pescadores. }\end{array}$ \\
\hline sector & $\begin{array}{l}\text { Repercusión positiva en la imagen de los proveedores por el uso de los } \\
\text { filtros y extintores adquiridos por la cofradía. }\end{array}$ \\
\hline Fuerza de marca & $\begin{array}{l}\text { Satisfacción para el personal laboral de formar parte de la entidad. } \\
\text { Valor emocional }\end{array}$ \\
\hline
\end{tabular}

Fuente: Elaboración propia.

La Tabla 2 recoge la descripción del conjunto de variables de valor, referidas al valor social específico. La desagregación de las perspectivas empleadas para su determinación puede visualizarse en la matriz de intereses de la Tabla 3. En la misma puede observarse que cinco de las variables de valor se han identificado desde ambas perspectivas, dos de ellas con un enfoque externo. 
Tabla 3. Matriz de intereses de los grupos de interés: perspectiva interna $(\mathrm{PI})$ y externa $(\mathrm{PE})$

\begin{tabular}{|c|c|c|c|c|c|c|c|c|c|}
\hline Variables de valor & & & & Sta & holc & $5(*)$ & & & \\
\hline & MR & AR & PA & TR & CL & VP & IM & AP & OC \\
\hline Servicio & $\mathrm{PI}$ & PE & & & $\mathrm{PI}$ & $\mathrm{PI}$ & & & \\
\hline Ventaja de precio & $\mathrm{PI}$ & $\mathrm{PE}$ & & & $\mathrm{PI}$ & & & & \\
\hline Divulgación & $\mathrm{PI}$ & PE & & & & PI & $\mathrm{PI}$ & & \\
\hline Apoyo & & & & & & PI & & $\mathrm{PI}$ & $\mathrm{PE}$ \\
\hline $\begin{array}{l}\text { Conocimiento ecológico y del } \\
\text { sector }\end{array}$ & & & & & & PI & & & PE \\
\hline Fuerza de marca & & & $\mathrm{PE}$ & & & & & & \\
\hline Valor emocional & & & & $\mathrm{PE}$ & & & & & \\
\hline
\end{tabular}

(*) MR: Marineros; AR: Armadores; PA: Proveedores de armadores; TR: trabajadores; CL: clientes; VP: Viceconsejería de Pesca; IM: Instituto Social de la Marina; AP: Autoridad Portuaria Provincial; OC: Instituto Oceanográfico de Canarias.

Fuente: Elaboración propia.

\subsection{Cuarta etapa: monetización de los outputs}

En la cuarta fase del proceso metodológico del SPOLY, se emplean instrumentos propios de la lógica difusa para expresar en términos monetarios el valor social de la Cofradía. En primer lugar, en cuanto al valor social específico o de no mercado, se identifican los outputs de la organización vinculados a las variables de valor a través de un proceso de reflexión intersubjetivo, coparticipado por el conjunto de agentes del equipo de AR, tomando de forma consensuada las decisiones sobre transformación de variables.

Ha de indicarse que se encuentran dificultades en la asignación de outputs a la variable Valor Emocional, no quedando la misma finalmente vinculada a producto alguno de la Cofradía. No obstante, se ha incluido en el análisis como una forma de avanzar en su visualización (Retolaza et al., 2014:28).

Posteriormente, se seleccionan las proxys, o ítems externos que permiten realizar una aproximación al valor monetario que los outputs podrían tener, atendiendo a la similitud o consideración del contexto social y temporal en el que los outputs se generan. Puesto que, en el modelo poliédrico de análisis de valor social, la elección de los proxys se realiza aplicando el valor razonable (Retolaza y San José, 2018:109), se toma como aproximación el precio de mercado de un output idéntico, o considerado similar por los expertos externos del equipo de AR, teniendo en cuenta la naturaleza específica del output. 
Por ejemplo, para los outputs "asesoramiento a los socios" o "filtros de los barcos" se dispone de outputs idénticos intercambiados en el mercado, mientras que "conocimiento del sector" o "fuerza de marca" se han equiparado a la obtención de información a través de una investigación de mercado realizada por una consultaría y el anuncio en una valla publicitaria, respectivamente.

Los criterios seguidos en la selección de las proxys han sido los característicos del modelo poliédrico (Retolaza et al, 2016:61): los costes o ahorros para la Administración ${ }^{29}$, la unidad territorial en que se ubica la Cofradía, y el período temporal concreto para el cual se reportan los datos (2017).

Por ejemplo, para "salario hora de un técnico biólogo marino" se ha tomado como proxy "retribución del personal investigador del Instituto Oceanográfico de Canarias", y para "precio por hora de la navegación", el de las empresas que proveen el mismo servicio, ubicadas en las proximidades de los puertos de la zona meridional de Tenerife.

En cuanto a la elección del valor del proxy, en los casos en que la variabilidad de dicho valor ha sido alta, se ha tomado la puntuación centroide, por optimizar ésta la centralidad de la función de pertenencia (Retolaza y San José, 2016b:41). Éste ha sido el criterio seguido para la elección del valor del asesoramiento a los socios o el anuncio en valla publicitaria.

29. Se consideran buenos proxys por representar la disposición a pagar de la Administración, en representación de la sociedad. 


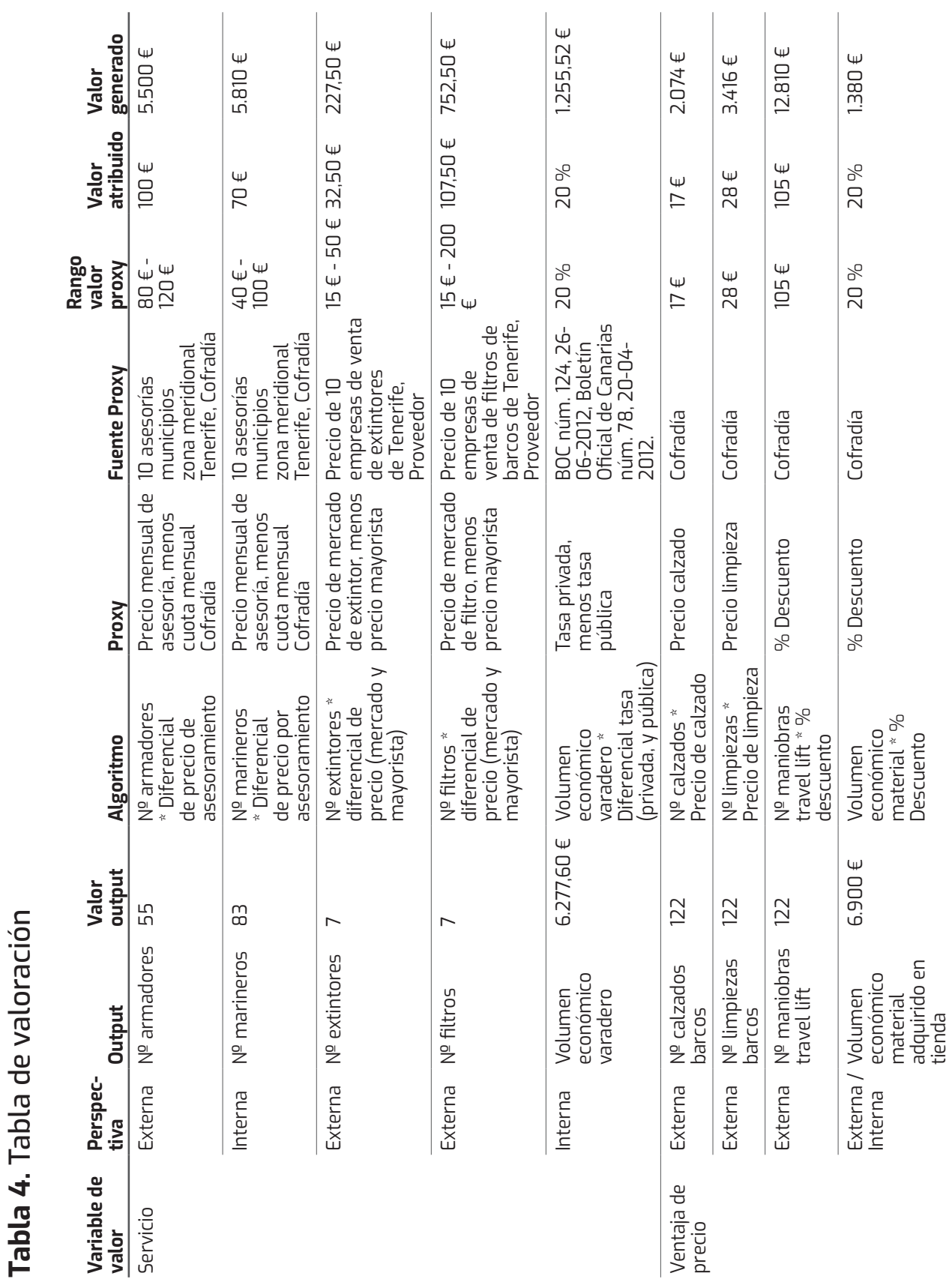




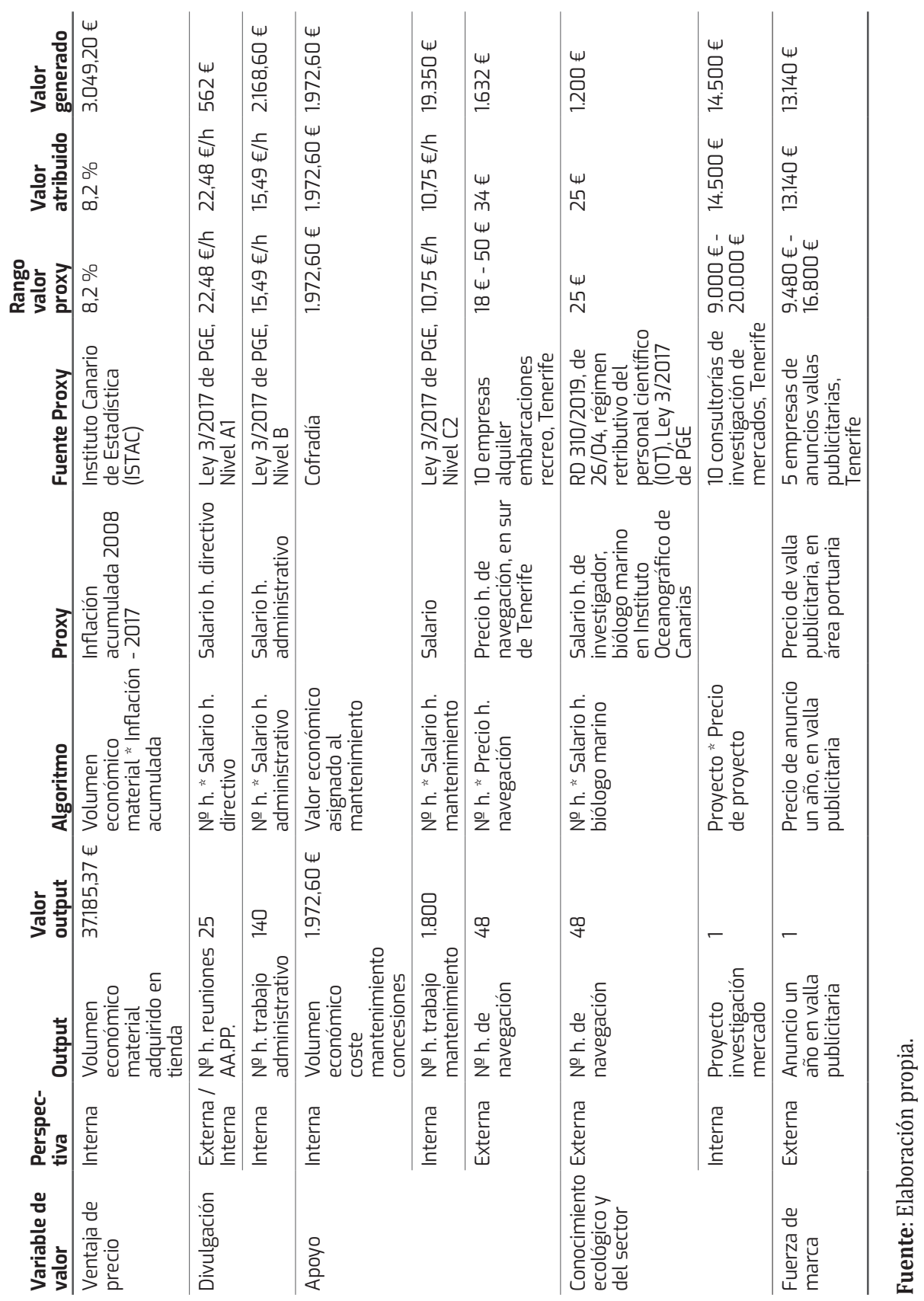


Finalmente, para la determinación monetaria de las variables de valor, se identifican los algoritmos relacionales entre los dos ítems, outputs y proxys (Retolaza et al, 2016:62), adoptando la forma de multiplicación en la mayor parte de los casos.

El conjunto de datos relativos a los campos anteriormente comentados se muestra en la Tabla 4. Puede observarse que es la tabla de valoración característica del modelo SPOLY (Retolaza et al., 2016b:63-64), si bien en este estudio se ha añadido una columna que proporciona información sobre la perspectiva que, en cada caso, se adopta para monetizar la dimensión del valor social. En última instancia, dicha columna permitiría agrupar, por un lado, el valor monetario de las variables de valor cuantificadas siguiendo un enfoque externo, y, por otro, el de las variables monetizadas bajo una perspectiva interna.

Posteriormente, se determina el ecosistema referido al valor social de mercado, siguiendo el proceso de cálculo estandarizado de sus dos componentes, el valor socio-económico directo y el indirecto (Retolaza et al., 2016). El valor social de mercado directo se cuantifica siguiendo el procedimiento del EVA (Gonzalo y Pérez, 2017:37-38; Retolaza et al., 2015:39). En el caso de la organización de estudio, en 2017 este valor asciende a 36.611,07 € (Tabla 5), distribuyéndose en forma de salarios a los trabajadores (18.042,70€), y cotizaciones a la Seguridad Social (14.758,72 €) y retención del IRPF (3.314,40 €), a la Administración Pública. La parte del valor añadido retenida en la entidad asciende a $-7.877,88 €$.

\section{Tabla 5. Valor socio-económico directo}

\begin{tabular}{llll} 
Variables & Indicador & Fuente & $\begin{array}{l}\text { Valor } \\
\text { monetario }\end{array}$ \\
\hline Salarios & Sueldos y salarios netos a empleados & Modelo 111 & $18.042,70 €$ \\
\hline Seguridad Social & $\begin{array}{l}\text { Seguridad Social (cofradía y } \\
\text { trabajador) }\end{array}$ & Contabilidad & $14.758,72 €$ \\
\hline Impuesto de la Renta & Retención IRPF & Modelo 111 & $3.314,40 €$ \\
\hline Otros Impuestos & Impuestos abonados & Contabilidad & $8.373,13 €$ \\
\hline Resultado & Beneficios antes de impuestos & Contabilidad & $-8.069,19 €$ \\
\hline Amortizaciones & Amortizaciones & Contabilidad & $191,1 €$ \\
\hline Valor socio-económico directo & & $\mathbf{3 6 . 6 1 1 , 0 7 €}$ \\
\hline
\end{tabular}

Fuente: Elaboración propia.

Por su parte, el valor socio-económico indirecto recoge el efecto tractor que la cofradía ejerce en el entorno a través de las adquisiciones de insumos a proveedores locales. La débil situación económico-financiera de la organización de estudio limita el volumen de compras efectuadas a otras entidades ${ }^{30}$.

30. La debilidad económico-financiera de la Cofradía repercute en la diversidad de servicios que ofrece a sus socios $y$, en última instancia, en el número de proveedores y el volumen de los abastecimientos. 
Para el cálculo de este componente del valor social de mercado, se realiza, en primer lugar, un análisis de la estructura de la distribución de valor de los proveedores locales de la Cofradía a través de datos mercantiles ${ }^{31}$ (Retolaza et al., 2015:40). Se determinan posteriormente los índices de repercusión (Tabla 6), que sirven de proxy para estimar la distribución de valor de los proveedores (Retolaza et al., 2015:25).

Por ejemplo, teniendo en cuenta que la facturación total de proveedores locales en el año 2017 fue de 2.342,60 €, se estima que el sumatorio de sueldos brutos correspondientes a esta facturación es de 512,16 €, que proviene de multiplicar la facturación de proveedores por $21,90 \%$, el índice de repercusión que expresa la media de gastos de personal de los proveedores de la entidad objeto de estudio.

\section{Tabla 6. Índices de repercusión}

\begin{tabular}{llllll} 
& $\begin{array}{l}\text { Gastos de } \\
\text { personal }\end{array}$ & $\begin{array}{l}\text { Valor } \\
\text { añadido }\end{array}$ & $\begin{array}{l}\text { Resultado } \\
\text { del ejercicio }\end{array}$ & Impuestos & $\begin{array}{l}\text { Facturación } \\
\text { proveedores }\end{array}$ \\
\hline Índices de repercusión & $21,9 \%$ & $25,4 \%$ & $1,6 \%$ & $0,6 \%$ & $100,0 \%$ \\
\hline
\end{tabular}

Fuente: Elaboración propia.

Como se muestra en la Tabla 7, el valor socio-económico indirecto de la cofradía en 2017 asciende a 604,93€, de los que 286,07€ constituyen un retorno a las Administraciones Públicas -en forma de cotizaciones a la Seguridad Social, retenciones del IRPF, impuestos, e Impuesto General Indirecto Canario (IGIC)-.

\section{Tabla 7. Valor socio-económico indirecto}

\begin{tabular}{llll} 
Variables & Indicador & Fuente & Valor monetario \\
\hline Gastos de personal & Sueldos y salarios netos a empleados & Proxy & $280,56 €$ \\
\hline Seguridad Social & Seguridad Social (empresa y trabajador) & 0,35 & $174,13 €$ \\
\hline Impuesto de la Renta & Retención IRPF & 0,17 & $57,46 €$ \\
\hline Otros Impuestos & Impuestos abonados & Proxy & $12,77 €$ \\
\hline IGIC & IGIC & 0,07 & $41,70 €$ \\
\hline Resultado & Resultado del ejercicio & Proxy & $38,30 €$ \\
\hline Valor socio-económico indirecto & & $\mathbf{6 0 4 , 9 3 €}$
\end{tabular}

Fuente: Elaboración propia.

31. Los datos mercantiles se extraen de la base de datos de la central de balances ibéricos (SABI). La entidad adquiere insumos de cinco organizaciones del entorno, y entre ellas, una figura en SABI. 


\subsection{Quinta etapa: consolidación contable}

En la última fase del proceso metodológico del SPOLY, se determina el Valor Social Integrado consolidando las distintas tipologías de valor social. Puesto que en este estudio se han combinado las perspectivas interna e interna para identificar y cuantificar en términos monetarios las variables de valor, se ha creído conveniente mantener dicha distinción en el Valor Social Integrado. (Tabla 8)

Por un lado, se ha obtenido el denominado Valor Social Integrado Externo, o suma del Valor Social de Mercado y del Valor Social Específico Externo (valor monetario del conjunto de variables de valor determinadas adoptando un enfoque externo). Y por otro, el Valor Social Integrado Externo e Interno, obtenido al añadir el valor monetario de las variables de valor cuantificadas siguiendo un enfoque interno, o Valor Social Específico Interno. En la Tabla 8 se observa que, a pesar del resultado de explotación negativo (- 8.069,19€), el blended value externo es positivo, 79.758,39 €.

\section{Tabla 8. Síntesis de resultados}

\begin{tabular}{ll} 
Ecosistemas de Valor & Valor generado \\
\hline Valor Socio-Económico Directo & $36.611,07 €$ \\
\hline Valor Socio-Económico Indirecto & $604,93 €$ \\
\hline Valor Social de Mercado & $37.216,00 €$ \\
\hline Valor Social Específico Externo & $42.542,39 €$ \\
\hline Valor Social Específico Interno & $48.257,53 €$ \\
\hline Valor Social Integrado Externo & $\mathbf{7 9 . 7 5 8 , 3 9 €}$ \\
\hline Valor Social Integrado Externo e Interno & $\mathbf{1 0 3 . 1 3 3 , 3 2} €$ \\
\hline
\end{tabular}

Fuente: Elaboración propia.

La distribución del Valor Social Integrado Externo e Interno, desagregado por tipologías de valor social, a los grupos de interés de la entidad se recoge en la Figura 3. Se observa que los colectivos que reciben un mayor retorno social son la Administración Pública y los armadores. Además, es relevante la contribución de la entidad a la generación y al reparto de valor a los proveedores locales y organismos de investigación. 


\section{Figura 3. Modelo Poliédrico de Análisis de Valor Social: Cofradía de Pes- cadores}

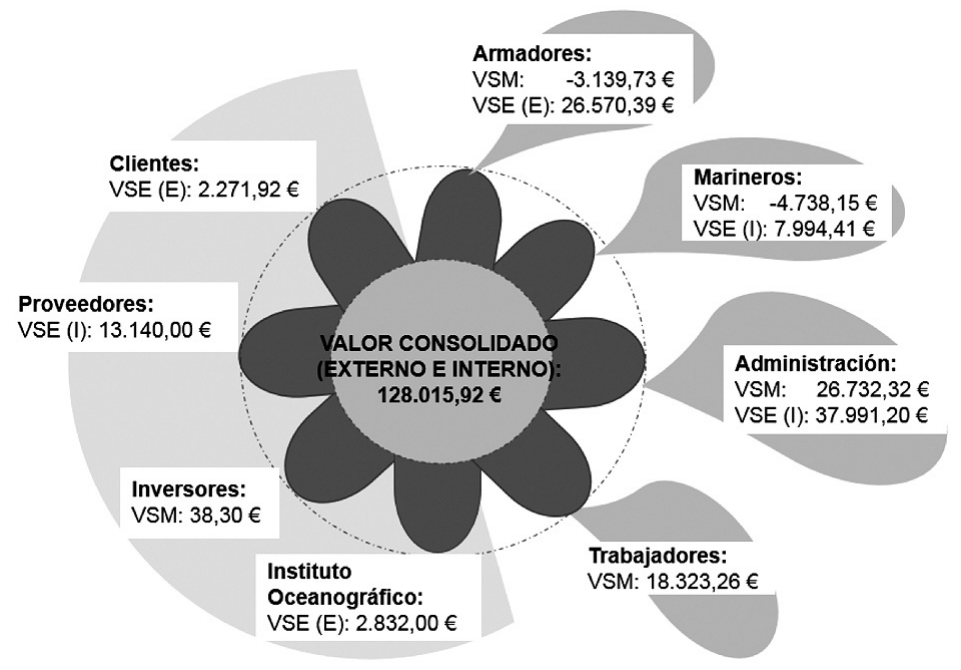

Fuente: Elaboración propia.

\section{Discusión y conclusiones}

Este trabajo se suma a los estudios empíricos recientes que tratan de determinar el impacto social de las entidades de Economía Social, para incrementar la eficiencia y eficacia en la gestión del desempeño sostenible (Bassi y Vincenti, 2015; Etxezarreta et al., 2018; Monzón et al. 2013; Retolaza et al., 2015; Retolaza y San-Jose, 2016), centrándose en una familia de entidades de economía social cuya contribución a la sostenibilidad apenas se ha explorado, las cofradías de pescadores.

En este estudio se ha cuantificado el valor social integrado de un caso particular, comprobándose que la organización consigue, a pesar de su situación económica deficitaria, generar un blended value positivo, desde el punto de vista de las percepciones de los grupos de interés. El resultado obtenido vendría a sumarse al de los trabajos que sostienen la capacidad de generación de valor socio-económico de las entidades de naturaleza social (Etxezarreta et al., 2018; Retolaza et al., 2014; Retolaza et al., 2015; Retolaza y San-Jose, 2016a), más allá del resultado económico financiero.

Puesto que la obtención de esta información de carácter cuantitativo, expresada en términos monetarios, es un primer paso para orientar la gestión hacia la sostenibilidad de la entidad 
en particular y, por extensión, de la rama del sector pesquero en la que se integra, es conveniente precisar los siguientes aspectos, particulares del caso de análisis.

En primer lugar, en relación con los grupos de interés de la Cofradía de estudio, se advierte la ausencia de determinados colectivos que, tras el análisis del marco jurídico del sector, habrían de figurar como agentes con los que la entidad se relaciona, o que resultan afectados por la misma. La debilidad financiera que la organización presenta vendría a explicar esta circunstancia, por impedirle llevar a cabo ciertas funciones atribuidas por la normativa nacional y autonómica en materia pesquera, como la prestación de servicios culturales a los cofrades o la promoción en la comunidad de los productos pesqueros regionales. Por tanto, parece plausible que el mapa de stakeholders obtenido para esta entidad podría aplicarse a otras organizaciones de naturaleza similar, si bien concebido como una base de mínimos sobre la cual adicionar colectivos.

En segundo lugar, en cuanto a los intereses de los stakeholders determinados internamente, podría existir un sesgo entre la percepción como valor por los agentes y lo que los miembros del equipo de AR han decidido de forma consensuada. Obviamente, constituye ésta una limitación del presente análisis que impediría extrapolar las variables de valor que han sido identificadas adoptando esta perspectiva. A este respecto, resultaría imprescindible entrevistar a los representantes de aquellos colectivos que, en el caso planteado, no ha sido posible. Ello permitiría comprobar que lo que se ha determinado internamente como valor es percibido realmente como tal, tanto para la cofradía de estudio como para otras entidades de esta familia de la economía social.

Por su parte, las variables de valor identificadas externamente vendrían a suponer el reconocimiento, por parte de los grupos de interés para los cuales se ha contado con evidencias primarias, del aporte de esta entidad de un valor transferido sin contrapartida de precio de mercado, en concreto: el servicio prestado a los armadores; el saber ecológico de los pescadores; y el prestigio, para organizaciones del siglo XXI, de que en unas embarcaciones artesanales y de bajura se utilicen sus productos.

Sobre la posibilidad de extrapolar a otras cofradías las variables de valor que, en este caso de estudio, han sido identificadas adoptando un enfoque externo, debe de tenerse en cuenta que el acercamiento al valor social desde el planteamiento ontológico de la teoría de los stakeholders se distingue por su carácter diferencial. Cada cofradía es considerada, por tanto, como una unidad diferenciada, susceptible de tener que responder a un conjunto peculiar y específico de intereses, los cuales pueden, además, variar a lo largo del tiempo.

Sin embargo, puesto que las organizaciones y sus stakeholders se encuentran profundamente relacionados, formando ecosistemas de intereses, el análisis de un conjunto agregado de organizaciones regionales de pescadores permitiría, en el paradigma fenomenológico, señalar variables de valor compartidas. Sería necesario, por tanto, aplicar la metodología del SPOLY a un número representativo de estos agentes en el territorio español, para configurar un cuadro de variables de valor que fuese común a todos ellos.

En la Cofradía analizada, cada uno de los colectivos ha visualizado el conjunto del valor social generado por la entidad desde su propia percepción, o perspectiva particular. Por lo 
que, para objetivar el valor social global, se han integrado las distintas aproximaciones de los stakeholders. En esta fase sintética del modelo de análisis de valor social, se han seleccionado las proxys utilizando como criterio de selección la similitud con los outputs generados (y percibidos como valor por los grupos de interés), para tratar de asegurar su validez y pertinencia. Por tanto, teniendo en cuenta el espacio geográfico y temporal en el que los outputs se han generado, se ha tomado el valor razonable, considerando además la conveniencia de la disposición a pagar por la Administración.

En relación con la elección de un valor del proxy, en los casos en que ha presentado una alta variabilidad, se ha tomado la puntuación centroide, si bien no se ha realizado el análisis de la variación de sensibilidad, por estar pendiente la cuestión en este modelo de cómo introducirlo sin hacer excesivamente complejo su cálculo (Retolaza et al., 2015:38).

Esta elección de proxys plantea ciertas limitaciones a la hora de extrapolar el caso de estudio a otras cofradías del territorio español. En particular, si bien podría tomarse como referencia los ítems financieros específicos aquí planteados, tendrían que estar referidos a los espacios geográficos y temporales en que los outputs se generen. En cualquier caso, y en coherencia con el enfoque fenomenológico, se requerirían más casos de entidades similares a la que aquí ocupa que, conjuntamente considerados, permitiesen avanzar también en la estandarización, tanto de proxys como de valores.

Por otra parte, cuando se comparan los resultados obtenidos para esta organización con los de otros entes de economía social, de naturaleza cooperativa y fundaciones, para las que se ha cuantificado el valor social que generan utilizando la Contabilidad Social (Etxezarreta et al., 2018; Retolaza et al., 2014; Retolaza et al.; 2015), podrían destacarse los siguientes aspectos.

En primer lugar, en relación con las variables de valor, se observan diferencias en las que intervienen en la determinación del valor socio-económico directo (omisión del IGIC o del Impuesto sobre Sociedades), explicadas por la pérdida económico-financiera de la Cofradía, no por serle de aplicación una fiscalidad especial (Etxezarreta et al., 2018).

Están también presentes las variables que reflejan los ahorros a la Administración derivados del ejercicio de la actividad del agente pesquero, si bien identificadas y monetizadas adoptando una perspectiva interna. Tales variables, comunes a las entidades de economía social (Etxezarreta et al., 2018; Retolaza et al., 2014; Retolaza et al.; 2015), reciben aquí otra denominación por razón de la misión de la Cofradía.

Por su parte, se aprecian similitudes entre la variable de valor Valor Emocional del personal laboral, y el sentimiento de pertenencia y la motivación de los trabajadores en el caso de la cooperativa social (Etxezarreta et al., 2018). Habrían de destacarse tres dimensiones específicas del valor social percibido de los stakeholders de la Cofradía que, debido a la naturaleza particular de esta entidad, no son compartidas por los colectivos de las otras organizaciones, a saber: el servicio a los armadores, la fuerza de marca a los proveedores y el conocimiento ecológico valorado por los investigadores marinos.

En segundo lugar, en cuanto al posicionamiento de las distintas tipologías de valor social, ha de indicarse que se aprecian diferencias entre la organización pesquera y la cooperativa social (Etxezarreta et al., 2018), concretadas en una mayor relevancia relativa del valor social espe- 
cífico en la Cofradía, frente a la del valor socio-económico en el de Etxezarreta et al. (2018). Esta discrepancia podría atender, no obstante, a ciertas especificidades presentes en ambos análisis, como el escaso despliegue de la actividad económica de la entidad pesquera o la reciente creación de la cooperativa social (Etxezarreta et al., 2018). Sería necesario, por tanto, en relación con este aspecto, ampliar el análisis a organizaciones de ambos tipos de familias de la economía social.

Podría considerarse como principal aportación de este trabajo el haber puesto de manifiesto ciertos aspectos que, una vez corroborados tras un análisis similar a un conjunto agregado de entidades de la misma naturaleza, permitirían orientar la toma de decisiones públicas y privadas hacia el incremento de la efectividad de las Cofradías para un desempeño sostenible. En concreto, cabría destacar tres variables de valor asociadas a la misión de la entidad, y que implican un reconocimiento en el siglo XXI del aporte a la sociedad de una entidad de origen medieval: el servicio prestado a sus socios, el saber ecológico de los pescadores, y el prestigio para las organizaciones del siglo XXI de que utilicen sus productos. En cualquier caso, las proxys propuestas para la monetización de los outputs, vinculados a tales variables de valor, deberían tener en cuenta las realidades espacio-temporales en las que aquéllos fuesen generados.

Las dos principales limitaciones presentes en este estudio, una única Cofradía y la identificación/monetización de ciertas variables de valor adoptando un enfoque interno, suponen realmente oportunidades para avanzar en esta línea de investigación en el archipiélago canario: aplicar la Contabilidad Social a otras organizaciones regionales de pescadores, presentes, de momento, en las islas, y que permitan obtener un cuadro común de variables de valor, como dimensiones del valor social percibido por sus grupos de interés.

\section{Bibliografía}

ALEGRET, J.L. (1989): “Del corporativismo dirigista al pluralismo democrático: las Cofradías de Pescadores en Cataluña", Revista ERES, Museo Etnográfico/Cabildo de Tenerife. Tenerife, 2, 161-172.

ANTELO, Á.P., VILLA, D. \& SANTOS, M. (2018): "Inmigración peruana y pesca en el puerto de Cambados (Galicia): una perspectiva de género". Boletín de la Asociación de Geógrafos Españoles, (76), 218-246. DOI: 10.21138/bage.2521

ASOCIACIÓN ESPAÑOLA DE FUNDACIONES (2015): Guía práctica para la medición y la gestión del impacto, Madrid: Asociación Española de Fundaciones.

AYUSO, S. (2018): La medición del impacto social en el ámbito empresarial, Cátedra MANGO de RSC ESCI-UPF Documento de trabajo, 26. 
AYUSO, S., SÁNCHEZ, P., RETOLAZA, J.L. \& FIGUERAS-MAZ, M. (2020). “Social value analysis: the case of Pompeu Fabra University". Sustainability Accounting, Management and Policy Journal, 11 (1), 233-252. DOI: https://doi.org/10.1108/SAMPJ-11-2018-0307

BARRIO, G.A. (1998): “Las cofradías de pescadores en el derecho español”, Anuario da Facultade de Dereito da Universidade da Coruña, 2, 161-188.

BASSI, A. \& VINCENTI, G. (2015): "Toward a new metrics for the evaluation of the social added value of social enterprises", CIRIEC-España, Revista de Economía Pública, Social y Cooperativa, 83, 9-42. Disponible en: https://www.redalyc.org/articulo.oa?id=174/17440036002

BONO, E. (2012): “El decrecimiento sostenible, crisis ecológico-económica, desigualdad y economía social”, CIRIEC-España, Revista de Economía Pública, Social y Cooperativa, 76, 180-196. Disponible en: https://www.redalyc.org/articulo.oa?id=174/17425849008

BOUCHARD, M. (coord.) (2010): The Worth of the Social Economy: An International Perspective, Series: Économie sociale \& Économie publique / Social Economy \& Public Economy: Peter Lang.

B0ZA, C. (2015): Pesca artesanal de la isla de Tenerife (Canarias): Análisis de la Primera Venta de los productos pesqueros y su influencia en el registro de datos biológicos, Tesis presentada y públicamente defendida para la obtención del título de Máster de Ciencias en Gestión Pesquera Sostenible, Universidad de Alicante.

CALDERÓN GIL, C.J. (2018). Análisis de la gestión socio-ambiental por parte de las cofradías de pescadores en la Comunidad Valenciana. Tesis presentada y públicamente defendida para la obtención del título de Máster en Evaluación Ambiental, Ecosistemas marinos y Costeros en la Universidad de Valencia.

CERVERA, A. (1988): "Nueve siglos de las Cofradías de Pescadores", Revista de Historia Naval, 61, 81-86.

CERVERA, A. (2006): Análisis estratégico de las Cofradías de Pescadores, Tesis Doctoral, Universidad de Cádiz.

CERVERA, A. (2010): "Percepción cooperativa de las cofradías de pescadores: un estudio empírico", REVESCO, Revista de Estudios Cooperativos, 103, 7-32.

Disponible en: https://www.redalyc.org/articulo.oa?id=367/36715601001

CHAVES, R. \& MONZÓN, J.L. (2012): "Beyond the crisis: the social economy, prop of a new model of sustainable economic development", Service Business, 6(1), 5-26.

CHAVES, R. \& MONZÓN, J.L. (2018): “La economía social ante los paradigmas económicos emergentes: innovación social, economía colaborativa, economía circular, responsabilidad social empresarial, economía del bien común, empresa social y economía solidaria", CIRIEC-España, Revista de Economía Pública, Social y Cooperativa, 93, 5-50. DOI: 10.7203/CIRIEC-E.93.12901. 
COMISIÓN EUROPEA (2011a): Comunicación de la Comisión al Parlamento Europeo, al Consejo, al Comité Económico Social Europeo y al Comité de las Regiones Estrategia renovada de la UE para 2011-2014 sobre la responsabilidad social de las empresas, Bruselas. Octubre.

COMISIÓN EUROPEA (2011b) 609 final -2011/070 (COD) (2012/CC 143/17): Dictamen del Comité Económico y Social Europeo sobre la "Propuesta de Reglamento del Parlamento Europeo y del Consejo relativo a un Programa de la Unión Europea para el Cambio y la Innovación Sociales".

COMISIÓN EUROPEA (2012) 494 final: Comunicación de la Comisión al Parlamento Europeo, al Consejo, al Comité Económico Social Europeo y al Comité de las Regiones. Crecimiento azul. Oportunidades para un crecimiento marino y marítimo sostenible, Bruselas. Septiembre.

COMISIÓN EUROPEA (2015): Métodos propuestos para la medición del impacto social en la legislación de la Comisión Europea y en la práctica relativa a FESE y EaSI, Luxemburgo, Comisión Europea - Dirección General de Empleo, Asuntos Sociales e Inclusión.

DECRETO 182/2004, de 21 de diciembre, por el que se aprueba el Reglamento de la Ley de Pesca de Canarias, BOC núm. 4 de 7 de enero de 2005.

DEFOURNY, J. \& DEVELTERE, P. (1999): "The social economy: the worldwide making of a third sector", Social economy North and South, 17-47.

DE MENDIGUREN, J. C. P., ETXARRI, E. E. \& ALDANONDO, L. G. (2008): “¿De qué hablamos cuando hablamos de Economía Social y Solidaria? Concepto y nociones afines", Presentado en XI Jornadas de Economía Crítica, Burgos: Cáritas Burgos.

DÍAZ, M., MARCUELLO, C. \& MARCUELLO, C. (2012): “Empresas sociales y evaluación del impacto social", CIRIEC-España, Revista de Economía Pública, Social y Cooperativa, 75, 179-198. Disponible en: https://www.redalyc.org/articulo.oa?id=174/17425798010

DICTAMEN 2009/C 318/05 del Comité Social y Económico Europeo sobre el tema «Distintos tipos de empresa» (Dictamen de iniciativa), Diario Oficial de la Unión Europea, 29 de diciembre 2009.

DUSKA, R.F. \& RAGATZ, J.A. (2008): "Purpose of Business", en Kolbo, R.W. (eds.) Purpose of Business, Los Angeles, USA: SAGE. 210-216.

EASTERBY-SMITH, M., THORPE, R. \& LOWE, A. (1991): Management Research: An Introduction, Londres: Sage Publications.

EBRAHIM, A. \& RANGAN, V.K. (2010): The Limits of Nonprofit Impact: A Contingency Framework for Measuring Social Performance, Social Enterprise Initiative Harvard Business School Working Paper 10-099. 
EMERSON, J., BONINI, S. \& BREHM, K. (2003): The blended value map: tracking the interests and opportunities of economic, social and environmental value creation, The William and Flora Hewlett Foundation Documento de trabajo.

ETXEZARRETA, E., MENDIGUREN, J.C.P., DÍAZ, L. \& ERRASTI, A. (2018): "Valor social de las cooperativas sociales: aplicación del modelo poliédrico en la cooperativa para la acogida de menores Zabalduz S.Coop", CIRIEC-España, Revista de Economía Pública, Social y Cooperativa, 93, 155-180, DOI: 10.7203/CIRIECE.93.9953.

EVERITT, B.S. (1984): An Introduction to Latent Variable Models, Londres, UK: Chapman and Hall.

FAO (1995): Código de Conducta para la Pesca Responsable.

Disponible en: http://www.fao.org/docrep/005/V9878S/V9878S00.HTM\#ANT

FAO (2016): El estado mundial de la pesca y la acuicultura 2016. Contribución a la seguridad alimentaria y la nutrición para todos, Roma: ONU.

FELBER, C. (2010): La Economía del Bien Común, Viena: Deusto.

FREEMAN, R.E. (1984): Strategic management a stakholder approach, Boston: Pitman.

FREEMAN, R.E., WICKS, A.C. \& PARMAR, B. (2004): "Stakeholder Theory and "The Corporate Objective Revisited", Organization Science, 15 (3), 364-369. D0I: https://doi.org/10.1287/ orsc. 1040.0066

FRIEDMAN, M. (1970): "The Social Responsibility of Business is to Increase its Profits", The New York Times Magazine, September 13.

FUSTER, D.E. (2019): "Investigación cualitativa: Método fenomenológico hermenéutico", Propósitos y Representaciones, 7 (1), 201-229. DOI: http://dx.doi.org/10.20511/pyr2019. v7n1.267

GALVÁN, A. (1982): "Aspectos sociológicos de las comunidades pesqueras canarias", La pesca en Canarias: II Jornadas de Estudios Económicos Canarios, 81-96.

GARCÍA ALLUT, A. (1999): “Compartición de conocimiento tradicional y científico para una gestión más adecuada de las pesquerías", Etnográfica, Vol. III (2), 309-331.

GARCÍA ALLUT, A. \& FREIRE, J. (2006): “Las cofradías, la comercialización y el cambio de paradigma (p. 141)", Presentado en Galicia \& Terranova \& Labrador: Comparative Studies on Economic, Political and Socio-cultural Processes: Proceedings of the International Congress, Santiago de Compostela, October 28-31, 2002, Univ Santiago de Compostela. 
GARCÍA-LORENZO, I. \& VARELA-LAFUENTE, M. (2019): Interacciones de gobernanza en las pesquerías a pequeña escala de Galicia: percepciones y dinámicas en las cofradías de pescadores. Estudios de Economía Aplicada, 37(3).

GARRIGA, E. (2014): "Beyond stakeholder utility function: stakeholder capability in the value creation process", Journal of Business Ethics, 120 (4), 489-507.

DOI: https://doi.org/10.1007/s10551-013-2001-y

GECES (2012): Report from first Meeting of the GECES sub-group on Social Impact Measurement (26/11/2012).

GIORGI, A. \& GIORGI, B. (2003): «Phenomenology», en SMITH, A. (ed.) Qualitative Psychology. Londres: Sage, pp. 25-50.

GONZALO, J.A. \& PÉREZ, J. (2017): “Una propuesta de normalización relativa al valor añadido como medida alternativa de rendimiento empresarial", XIX Congreso Internacional AECA, Santiago de Compostela, 27 a 29 de septiembre.

HERNÁNDEZ, S. (2014): El papel de las cofradías de pescadores en la gestión sostenible del sector pesquero, Trabajo Fin de Master, Universidad Politécnica de Cartagena, Facultad de Ciencias de la Empresa.

HURWICZ, L. (1951): "Some specification problems and applications to econometric models", Econometrica, 19(3), 343-344.

HUSSERL, E. (1990): Ideas pertaining to a pure phenomenology and to a phenomenological philosophy: studies in the phenomenology of constitution, Springer.

KATZ, D. \& KAHN, R.L. (1966): Organizations, New York: John Wiley and Sons.

KAUFMANN, A. \& GIL ALUJA, J. (1986): Introducción de la teoría de los subconjuntos borrosos a la gestión de las empresas, Santiago de Compostela, Spain: Milladoiro.

LAZCANO, L., SAN-JOSE, L. \& RETOLAZA, J.L. (2019): "Social Accounting in the Social Economy: A Case Study of Monetizing Social Value", In: Modernization and Accountability in the Social Economy Sector (pp. 132-150). IGI Global. D0I: 10.4018/978-1-5225-8482-7.ch008

LEWIN, K. (1946): "Action research and minority problems", Journal of Social Issues, 2 (4), 34-46.

LEY 3/2001, de 26 de marzo, de Pesca Marítima del Estado, modificada por la Ley 33/2014, de 26 de diciembre

LEY 17/2003, de 10 de abril, de Pesca de Canarias, BOC núm. 77 de 23 de abril de 2003.

LEY 5/2011, de 29 de marzo, de Economía Social. BOE núm. 76, de 30 de marzo de 2011. 
MACÍAS, A.J. (2018): La economía social y el desarrollo sostenible, un camino común que marcan sus principios, XVII Congreso Internacional de Investigadores en Economía Social y Cooperativa, Toledo, 4-5 de octubre.

MAPAMA (2007): Plan Estratégico Nacional del Fondo Europeo de la Pesca, Madrid: Secretaría General de Pesca Marítima.

MELÉ, D. (2009): "The view and the purpose of the firm in Freeman's stakeholder theory", Philosophy of Management, 8 (3), 3-13. D0I: https://doi.org/10.5840/pom2009832

MÉNDEZ, M.D. (2018): "Las cofradías de pescadores como organizaciones pesqueras y su influencia socioeconómica en la pesca de bajura en España", Alimentación \& bebidas (Food \& beverages), 2, 307-321. Madrid: Thomson Reuters Aranzadi.

MISHAN, Q. (2007): Cost benefit analysis. New York: Routledge.

MONZÓN, J. L. (2013): “Empresas sociales y economía social: perímetro y propuestas metodológicas para la medición de su impacto socioeconómico en la UE", Revista de Economía Mundial, 35, 21-45. Disponible en: https://www.redalyc.org/articulo.oa?id=866/86629567008.

MONZÓN, J.L. \& MARCUELLO, C. \& NACHAR, P. (2013): Empresas sociales y economía social: propuestas metodologicas para la medicion de su impacto socio-económico, Bruselas, CESE.

NACHAR, P. (2013): Sociedades Cooperativas, una Aproximación desde la Responsabilidad Social Corporativa y el Desarrollo, Tesis Doctoral, Universidad de Zaragoza.

OLSEN, S. \& GALIMIDI, B. (2008): Catalog of Approaches to Impact Measurement: Assessing Social Impact in Private Ventures, Social Venture Technology Group.

PASCUAL, J. (1999): "Los estudios de antropología de la pesca en España: nuevos problemas, nuevas tendencias", Etnográfica, Vol. III (82), 333-359.

POPESCU, I. \& ORTEGA, J.J. (2013): La Pesca en las Islas Canarias, Parlamento Europeo, Dirección General de Políticas Interiores.

PORTER, M.E. \& KRAMER, M.R. (2011): “Creating Shared Value”, Harvard Business Review, 89(1/2), 62-77.

POUDEL, S., NYAUPANE, G. P. \& BUDRUK, M. (2016): "Stakeholders' perspectives of sustainable Tourism development: A new approach to measuring outcomes", Journal of Travel Research, 55(4), 465-480. DOI: 10.1177/0047287514563166

RANDLE, E.J. \& HOYE, R. (2016): "Stakeholder perception of regulating commercial tourism in Victorian National Parks, Australia", Tourism Management, 54, 138-149.

DOI: https://doi.org/10.1016/j.tourman.2015.11.002. 
RETOLAZA, J.L, RUIZ-ROQUEÑI, M., SAN-JOSE, L. \& BARRUTIA, J. (2014): “Cuantificación del valor social: propuesta metodológica y aplicación al caso de Lantegi Batuak", Revista de servicios sociales, 55, 17-33. D0I: http://dx.doi.org/10.5569/1134-7147.55.02.

RETOLAZA, J.L, RUIZ-ROQUEÑI, \& M. SAN-JOSE, L. (2015): "Monetarizing the social value: theory and evidence", CIRIEC-España Revista de Economía Pública, Social y Cooperativa, 83, 4362. Disponible en: https://www.redalyc.org/articulo.oa?id=174/17440036003.

RETOLAZA, J.L, SÁNCHEZ, P., TARIFA, P., RUIZ-ROQUEÑI, M., SAN-JOSE, L. \& AYUSO, S. (2015): Análisis del valor social de la Fundación Formació $i$ Trebal: Una aproximación monetaria al cálculo del valor social, Cátedra Mango Documento de trabajo 22.

RETOLAZA, J.L. \& SAN-JOSÉ, L. (2011): "Social economy and stakeholder theory, an integrative framework for socialization of the capitalism", CIRIEC-España, Revista de Economía Pública, Social y Cooperativa, 73, 193-211.

Disponible en: https://www.redalyc.org/articulo.oa?id=174/17421160010

RETOLAZA, J.L. \& SAN-JOSÉ, L. (2016a): “Contabilidad social para la sostenibilidad: modelo y aplicación", Revista de Contabilidad y Dirección, 23, 159-178.

RETOLAZA, J.L. \& SAN-JOSÉ, L. (2016b): Contabilidad Social orientada a los stakeholders. Perspectiva de la Administración Pública. Madrid: Pirámide.

RETOLAZA, J.L. \& SAN-JOSÉ, L. (2018): “Contabilidad Social para el Bien Común”, Responsabilidad Social de la Empresa, 29, 95-122.

RETOLAZA, J.L. SAN-JOSÉ, L. \& LAMARQUE, E. (2018). “The Social Efficiency for Sustainability: European Cooperative Banking Analysis", Sustainability, 10(9), 3271.

DOI:10.3390/su10093271

RETOLAZA, J.L., SAN-JOSE, L. \& RUIZ-ROQUEÑI, M. (2016): Social Accounting for Sustainability: Monetizing the Social Value, Springer Briefs in Business, Springer.

SAN-JOSE, L., RETOLAZA, J.L. \& BERNAL, R. (2019). Social value added index: a proposal for analyzing hospital efficiency. Gaceta sanitaria de 24 de noviembre de 2019.

D0I: $10.1016 /$ j.gaceta.2019.08.011

ROSENZWEIG, W. (2004). Double Bottom Line Project Report: Assessing Social Impact in Double Bottom Line Ventures. Working Paper Series University of Berkeley 13.

SANTAMARÍA, M.T.G., JIMÉNEZ, S., GONZÁLEZ, J.F., FALCÓN, J.M. \& VILLEGAS, N. (2014): Proyecto GEPETO. Resultados del Caso de Estudio 7: Pesquerías Artesanales de las Islas Canarias. Tenerife, Instituto Español de Oceanografía. Centro Oceanográfico de Canarias. Memoria Científico-Técnica. 106 pp. 
SEC (2011) 1512/2. Commission Staff Working Paper Impact Assessment Accompanying the document Proposal for a Regulation of the European Parliament and of the Council on European Social Entrepreneurship Funds.

SUÁREZ DE VIVERO, J.L. (2011): An atlas of maritime spatial planning, Canary Islands subdivision, 151-169.

TREJO, F. (2012): “Fenomenología como método de investigación: Una opción para el profesional de enfermería”, EnfNeurol (México), 11 (2), 98-101.

UE (2013): Reglamento (UE) n.o 1380/2013 del Parlamento Europeo y del Consejo, de 11 de diciembre de 2013, sobre la política pesquera común, por el que se modifican los Reglamentos (CE) n.o 1954/2003 y (CE) n.․ 1224/2009 del Consejo, y se derogan los Reglamentos (CE) n.. 2371/2002 y (CE) n.․ 639/2004 y la Decisión 2004/585/CE del Consejo.

UN (2002): Informe de la Cumbre Mundial sobre el Desarrollo Sostenible, Naciones Unidas: Nueva York.

UN (2012): The future we want, Resolution of General Assembly 66/288, 27 July 2012.

VARONA, M. (1995): “Sociedades de Socorros Mutuos", El Mar, 331, sept.

VIDAL, D., PITA, P., FREIRE, J. \& MUIÑO, R. (2020): Understanding Fishermen-Scientist Collaboration in Galician Small-Scale Fisheries (NW Spain): Validating a Methodological Toolbox Through a Process-Oriented Approach, en Collaborative Research in Fisheries (pp. 61-84). Springer, Cham.

WORLD COMMISSION ON ENVIRONMENT AND DEVELOPMENT (1987): Our Common Future, New York, USA: Oxford University Press.

ZADEH, L.A. (1965): “Fuzzy Sets”, Information Control, 8: 338-353. 